\title{
The Effect of Temperature on the Preferential Intergranular Oxidation Susceptibility of Alloy 600
}

\author{
G. BERTALI, M.G. BURKE, F. SCENINI, and N. HUIN
}

Oxidation studies were performed on solution-annealed Alloy 600 in high-temperature steam at $400{ }^{\circ} \mathrm{C}$ and in simulated pressurized water reactor primary water at $320^{\circ} \mathrm{C}$ under environmental conditions where this alloy is known to be susceptible to intergranular stress corrosion cracking. Advanced analytical transmission electron microscopy characterization and detailed scanning electron microscopy analysis highlighted extensive preferential intergranular oxidation as well as enhanced $\mathrm{Cr}$ and $\mathrm{O}$ diffusivities associated with this oxidation. These findings, as well as the preferential intergranular oxidation susceptibility and diffusion-induced grain boundary migration, are discussed in terms of their roles as precursors to stress corrosion cracking.

https://doi.org/10.1007/s11661-018-4491-9

(c) The Author(s) 2018. This article is an open access publication

\section{INTRODUCTION}

AlLOY 600 primary water stress corrosion cracking (SCC) has been a major in-service issue over the past decades ${ }^{[1-3]}$ since it was first observed by Coriou et al. in 1959. ${ }^{[4]}$ Since then numerous laboratories have shown that Alloy 600 is susceptible to intergranular stress corrosion cracking (IGSCC) in simulated pressurized water reactor (PWR) primary water environments, and that its maximum susceptibility occurs in the electrochemical potential region close to the $\mathrm{Ni} / \mathrm{NiO}$ transition. ${ }^{[5-8]}$ The nominal operating temperature in the PWR primary water circuit ranges from 286 to $322{ }^{\circ} \mathrm{C}$, and $345{ }^{\circ} \mathrm{C}$ in the pressurizer, ${ }^{[9]}$ however, the incubation time for IGSCC at these plant-relevant temperatures could be several years, if not decades, and laboratory tests may not be feasible for such long timescales. Therefore, there is the need to accelerate this degradation phenomenon in order to investigate and understand the degradation mechanism. Laboratory tests are generally performed in high-purity deoxygenated water at temperatures up to $360^{\circ} \mathrm{C}$, which is a practical maximum temperature that is below the supercritical point $\left(374{ }^{\circ} \mathrm{C}\right)$ of water. However, considering that the $\mathrm{SCC}$ is thermally activated and that the activation energy is in the range of 30 to $70 \mathrm{kcal} / \mathrm{mol}(125$ to $290 \mathrm{~kJ} / \mathrm{mol}),{ }^{[10]}$ there is a need to perform tests above the critical temperature of water, i.e., in a steam environment, in

G. BERTALI, M.G. BURKE, and F. SCENINI are with the Material Performance Centre, The University of Manchester, Manchester, M13 9PL UK. Contact e-mail: Giacomo.bertali@ manchester.ac.uk N. HUIN is with the Areva NP, 71200, Le Creusot, France.

Manuscript submitted April 25, 2017.

Article published online February 21, 2018 order to achieve more rapid IGSCC initiation. Above the supercritical temperature water is known to have very different physical properties ${ }^{[11]}$ and it could be argued that this will have an effect on the mechanism of SCC. However, Economy et al. ${ }^{[12]}$ proposed that the SCC mechanism was unchanged between tests in pressurized water $\left(310{ }^{\circ} \mathrm{C}\right.$ to $\left.360{ }^{\circ} \mathrm{C}\right)$ and supersaturated steam $\left(360{ }^{\circ} \mathrm{C}\right.$ to $\left.400{ }^{\circ} \mathrm{C}\right)$ based on their observation that the time-to-failure for Alloy 600 reverse u-bend samples followed a linear dependence in the Arrhenius plot for the entire temperature range. Moreover, Economy et $a l .{ }^{[12]}$ observed similar fracture morphologies in the two environments and concluded that the same cracking mechanism was active for both conditions. More recently Moss et al. ${ }^{[13]}$ reported a similar behavior for both Alloys 600 and 690 tested in subcritical and supercritical water. They observed that the mechanism for SCC initiation in both alloys was consistent between hydrogenated subcritical and supercritical water. In addition to these findings, Lindsay et al. ${ }^{[14]}$ performed other tests to further investigate the similarities in the SCC mechanism for Alloy 600 in both high-pressure steam and low-pressure $\mathrm{H}_{2}$-steam. They conducted constant active load tests on cold-rolled Alloy 600 dog-bone samples at $400{ }^{\circ} \mathrm{C}$ in a low-pressure $\mathrm{H}_{2}$-steam environment and observed an electrochemical potential dependence similar to the one reported for high-pressure steam at $400{ }^{\circ} \mathrm{C} .{ }^{[12,13]}$

The fact that the maximum SCC susceptibility occurs at potentials in the vicinity of the $\mathrm{Ni} / \mathrm{NiO}$ transition has been suggested to be associated with a less protective and unstable $\mathrm{Ni}$ oxide at this electrochemical potential, which, in turn, strongly influences IGSCC. ${ }^{[15]}$ Among all the models proposed for the occurrence of Alloy 600 IGSCC initiation, the Internal Oxidation model by Scott and Le Calvar ${ }^{[16,17]}$ appears to be the most 
comprehensive; nonetheless, some authors argued that $\mathrm{O}$ and $\mathrm{Cr}$ grain boundary (GB) diffusion coefficients in $\mathrm{Ni}$ alloys ${ }^{[18,19]}$ extrapolated to the temperatures of interest for primary water SCC were several orders of magnitude lower than those required to justify the experimentally observed crack growth rate in PWR primary water. ${ }^{[20,21]}$ Consequently, the Internal Oxidation model has evolved over the years, and recent studies have shown that intergranular oxidation of $\mathrm{Cr}^{[22-30]}$ occurs during accelerated SCC initiation tests; thus, the SCC initiation can be more aptly described as preferential intergranular oxidation (PIO). ${ }^{[30]}$ Although the PIO mechanism is able to readily explain the Alloy 600 IGSCC phenomenon, it could not explain experimental observations by Fujii et al. and Lozano-Perez et al. ${ }^{[21,24]}$ concerning the experimentally measured $\mathrm{O}$ diffusion coefficient in Alloy 600SA, which was in disagreement with the value extrapolated from higher temperature data. It was therefore suggested that in order to get such rapid intergranular oxidation and a realistic SCC crack growth rate, a mechanism responsible for an enhanced $\mathrm{O}$ and $\mathrm{Cr}$ diffusivity must be active at temperatures relevant to PWR primary water environment.

Several independent laboratories have observed local perturbations of grain boundaries in Alloy 600 and Alloy 690 associated with intergranular oxide penetrations. ${ }^{[30-35]}$ In particular, recent studies by Bertali et $a .^{[30]}$ have unequivocally demonstrated the occurrence of pronounced grain boundary (GB) migration (lateral movement by $\sim 300 \mathrm{~nm}$ in 120 hours) during oxidation of Alloy 600SA in a high-temperature $\left(480{ }^{\circ} \mathrm{C}\right) \mathrm{H}_{2}$-steam environment. They detected fine intergranular $\mathrm{M}_{23} \mathrm{C}_{6}$ carbides, formed during the waterquench, that served as "markers" denoting the original boundary position and enabled GB movement away from the carbides during the high-temperature exposure to be measured, thereby confirming that GB migration occurred during the high-temperature oxidation. Furthermore, they suggested that this mechanism could play an important role in the IGSCC initiation process and in enhancing the $\mathrm{O}$ and $\mathrm{Cr}$ diffusivities. Although the first conclusive demonstration of this localized DIGM occurring in advance of the PIO was obtained at $480{ }^{\circ} \mathrm{C}$ in a $\mathrm{H}_{2}$-steam slightly reducing environment with respect to the $\mathrm{Ni} / \mathrm{NiO}$ transition, ${ }^{[30,34,35]}$ it was considered that the temperature of the tests $\left(480^{\circ} \mathrm{C}\right)$ was too high and that this might change the dominant mechanism responsible for IGSCC initiation.

Therefore, the present work focuses on understanding the temperature dependence of the initial stages of PIO. Particular attention has been given to characterization of localized GB migration and the associated local compositional variations occurring in solution-annealed (SA) Alloy 600. Tests were performed in simulated primary water at $320^{\circ} \mathrm{C}$ and high-pressure hydrogenated-steam at $400{ }^{\circ} \mathrm{C}$. These specimens were subsequently characterized via advanced analytical electron microscopy. The results are discussed in terms of DIGM, local GB enrichments and depletions, and similarities with the oxidation behavior of Alloy 600 in low-pressure $\mathrm{H}_{2}$-steam at $480{ }^{\circ} \mathrm{C}$.

\section{EXPERIMENTAL PROCEDURES}

\section{A. Material and Sample Preparation}

The Alloy 600 used in this study was manufactured by B\&W Tubular Products Division and supplied by Westinghouse Electric Corp. This material was provided in the low-temperature mill-annealed condition, and the bulk composition is reported in Table I.

The material was subsequently solution-annealed in air at $1100{ }^{\circ} \mathrm{C}$ for 30 minutes and water-quenched to room temperature within 10 seconds in order to produce a coarse-grained, fully recrystallized microstructure with limited intergranular carbide precipitation. Oxidation coupons of dimensions $30 \times 20 \times 4 \mathrm{~mm}$ were cut from the heat-treated plate several millimeters away from the oxidized surfaces in regions where any pre-oxidation and consequent solute depletion (e.g., of $\mathrm{Cr}$ ) had not occurred.

The samples were ground using SiC papers from 120 to 4000 grit, mechanically polished with diamond paste (3 and $1 \mu \mathrm{m}$ ), subsequently cleaned with detergent and water, and then ultrasonically cleaned for 15 minutes in deionized water. A final mechanical polish using $60 \mathrm{~nm}$ $\mathrm{SiO}_{2}$ Oxide Polishing Suspension (OPS) was performed in order to obtain a strain-free surface by removing any surface deformation induced by abrading procedure and not fully removed by the $1 \mu \mathrm{m}$ diamond paste polishing. It is known that a deformed surface layer has an impact on the oxidation behavior of stainless steels and Ni-base alloys. ${ }^{[36]}$ After final polishing, the samples were ultrasonically cleaned in deionized water to remove any Silica Oxide Polishing Suspension contamination, and then dried in a stream of cold air. The specimens were analyzed prior to exposure in order to ensure they were free from oxidation and the detailed base-material characterization is reported elsewhere. ${ }^{[25,30,33]}$

\section{B. Experimental Conditions}

The polished coupons were tested at two different temperatures that resulted in two different environments: high-pressure hydrogenated-steam ("sample A") and PWR-simulated primary water ("sample B"). The experiments were conducted in environments for which the dissolved $\mathrm{H}_{2}$ was closely monitored to remain just below the $\mathrm{Ni} / \mathrm{NiO}$ equilibrium potential.

In the present paper no electrochemical corrosion potential measurements were performed; however, the electrochemical potential vs $\mathrm{Ni} / \mathrm{NiO}$ can be accurately calculated from the knowledge of dissolved $\mathrm{H}_{2}$. In fact, it is well known that in deoxygenated and hydrogenated water (with dissolved $\mathrm{H}_{2}>0.5 \mathrm{ppb}$ ) noble metals such as $\mathrm{Pt}$, as well as passive metals such as austenitic stainless steels and Ni-base alloys, behave as a hydrogen electrode, and their EcP can be calculated from the Nernst equation. ${ }^{[37]}$ The reason for this is because the exchange current density for the $\mathrm{H}^{+} / \mathrm{H}_{2}$ reaction is greater than the passive current density of the metal. Furthermore, while the value of EcP expressed $v s$ the standard hydrogen electrode (SHE) would require the knowledge of the dissolved $\mathrm{H}_{2}$ and $\mathrm{pH}$, the potential EcP expressed 
Table I. Alloy 600SA Composition (Weight Percent)

\begin{tabular}{lcccccccccccc}
\hline Heat No. & $\mathrm{C}$ & $\mathrm{Mn}$ & $\mathrm{S}$ & $\mathrm{P}$ & $\mathrm{Si}$ & $\mathrm{Cr}$ & $\mathrm{Ni}$ & $\mathrm{Cu}$ & $\mathrm{Co}$ & $\mathrm{Fe}$ & $\mathrm{Ti}$ & $\mathrm{Al}$ \\
\hline 93510 & 0.047 & 0.23 & 0.002 & 0.005 & 0.30 & 15.42 & bal & 0.01 & 0.057 & 8.94 & 0.34 & 0.19 \\
\hline
\end{tabular}

$v s$ the $\mathrm{Ni} / \mathrm{NiO}$ transition $\left(\mathrm{EcP}_{v s . \mathrm{Ni} / \mathrm{NiO}}\right)$ is not dependent on the $\mathrm{pH}$ but solely on the dissolved $\mathrm{H}_{2}$ in the system. ${ }^{[38,39]}$ Further thermodynamic considerations, as well as the value of dissolved $\mathrm{H}_{2}$ and $\mathrm{H}_{2}$ fugacity required to be at the $\mathrm{Ni} / \mathrm{NiO}$ transition are discussed in the publications by Morton et al. ${ }^{[38,39]}$ and by Moss and Was. ${ }^{[40]}$

Several Alloy 600SA coupons were exposed to simulated PWR primary water at $320{ }^{\circ} \mathrm{C}$ for 1000 hours with $40 \mathrm{cc} / \mathrm{kg}$ (3.64 ppm) of dissolved $\mathrm{H}_{2}$, which corresponds to an equilibrium potential more reducing than the $\mathrm{Ni} / \mathrm{NiO}$ equilibrium potential, ${ }^{[41,42]}$ and with addition of $\mathrm{H}_{3} \mathrm{BO}_{3}(1200 \mathrm{ppm})$ and $\mathrm{LiOH}(2 \mathrm{ppm})$. The tests in simulated PWR primary water were performed in a static $9 \mathrm{~L}$ stainless steel autoclave that was equipped with a Pd-23 pct Ag thimble, which was used to monitor and control the $\mathrm{H}_{2}$ fugacity in the water to the required experimental conditions. In order to achieve the required value of dissolved $\mathrm{H}_{2}$ at temperature, the autoclave was filled with the solution, deaerated by purging with $\mathrm{N}_{2}$ gas at room temperature for 24 hours and pre-charged with $70 \mathrm{kPa}$ of $\mathrm{H}_{2}$. This is known to provide the required value of dissolved $\mathrm{H}_{2}$. At $320{ }^{\circ} \mathrm{C}$ the measured $\mathrm{H}_{2}$ fugacity was $42.76 \mathrm{kPa}$ and the electrochemical corrosion potential of Alloy 600 was on the reducing side of the $\mathrm{Ni} / \mathrm{NiO}$ transition. ${ }^{[39]}$ The total pressure in the autoclave at $320{ }^{\circ} \mathrm{C}$ was $11.3 \mathrm{MPa}$. The same material was also tested in high-pressure hydrogenated-steam at $400{ }^{\circ} \mathrm{C}$ for 500 hours using the same $9 \mathrm{~L}$ stainless steel autoclave used for the water oxidation and following the same procedure. However, for the $\mathrm{H}_{2}$-steam exposure, the $\mathrm{H}_{2}$ fugacity was adjusted and monitored to be at $70 \mathrm{kPa}$ at a steam pressure of 20 $\mathrm{MPa}$. Using the thermodynamic approach reported by Ecomomy and Jacko ${ }^{[12]}$ and Scenini et al., ${ }^{[36]}$ the oxygen partial pressure in $\mathrm{H}_{2}$-steam was calculated to be $1.89 \times 10^{-23} \mathrm{~Pa}$ which is lower than the dissociation partial pressure of the $\mathrm{NiO}\left(3.22 \times 10^{-23} \mathrm{~Pa}\right)$ and, consequently, the environment was more reducing than the $\mathrm{Ni} / \mathrm{NiO}$ transition. The main reason for maintaining conditions to be more reducing than the $\mathrm{Ni} / \mathrm{NiO}$ transition was to make the test relevant to typical PWR operation.

\section{Microstructural Characterization}

Several complementary analytical techniques, including scanning electron microscopy (SEM), energy dispersive X-ray spectroscopy (EDX), electron backscatter diffraction, focused ion beam (FIB) milling, and analytical transmission electron microscopy were used to characterize the specimens and near-surface microstructure.
The as-polished post-exposure sample surfaces were characterized using a Zeiss Merlin field emission gun SEM equipped with two Oxford Instruments X-Max 150 silicon drift detector for EDX microanalysis, an Oxford Instruments Extreme 100 windowless low voltage silicon drift detector and Aztec analysis system. An FEI Helios NanoLab 660 DualBeam FIB was used in the cross-section selected grain boundaries in order to observe the microstructure in the near-surface region using a Through-Lens Detector, a Mirror Detector and an In-Column Detector at high $(20 \mathrm{kV})$ and low accelerating voltages ( 3 to $5 \mathrm{kV}$ ).

The cross-section specimens were extracted from the coupons using the TEM lift-out technique and thinned to electron transparency using the FIB. Initial analytical electron microscopy characterization of the these FIB-prepared specimens was performed using an FEI Tecnai G2 T20 $\mathrm{LaB}_{6}$ analytical TEM operated at $200 \mathrm{kV}$ and equipped with an Oxford Instruments windowless X-Max 80 TLE silicon drift detector and Aztec analysis system. Discrete STEM-EDX "spot" analyses were performed using a 60-second acquisition (live) time-to-measure composition at various locations along the grain boundaries. Additional analyses were performed at $200 \mathrm{kV}$ using an FEI Talos F200X S/TEM with an X-FEG and Super $\mathrm{X}$ EDX (four silicon drift detectors) for improved X-ray collection and EDX spectrum imaging analysis. For EDX spectra quantification the Cliff-Lorimer technique using a theoretical K factors with respect to Si calculated for 200 $\mathrm{kV}$ was used. All spectra were background-subtracted and the FWHM (full width half-max) integrated intensities were used for quantification. All STEM-EDX microanalyses were performed using the Oxford Instruments X-max 80 TLE Si drift detector on electron-transparent (thickness $<100 \mathrm{~nm}$ ) and TEMQUANT software (which utilizes a top-hat filter for peak deconvolution).

\section{RESULTS}

\section{A. SEM Characterization of the Oxidized Surface}

The surfaces of the oxidized coupons were immediately characterized after the exposure using the SEM. The appearance of the oxidized sample A and sample B surfaces are shown in Figures 1 and 2, respectively. For both exposure conditions there was no evidence of a continuous surface oxide, and the grain structure could be readily identified via conventional secondary electron (SE) imaging of the sample surface. The absence of a continuous surface oxide was expected, considering that the electrochemical potential was maintained well below the $\mathrm{Ni} / \mathrm{NiO}$ oxidation potential; hence, $\mathrm{NiO}$, which is a necessary phase for the formation of an external layer in this environment could not form. ${ }^{[42]}$ 

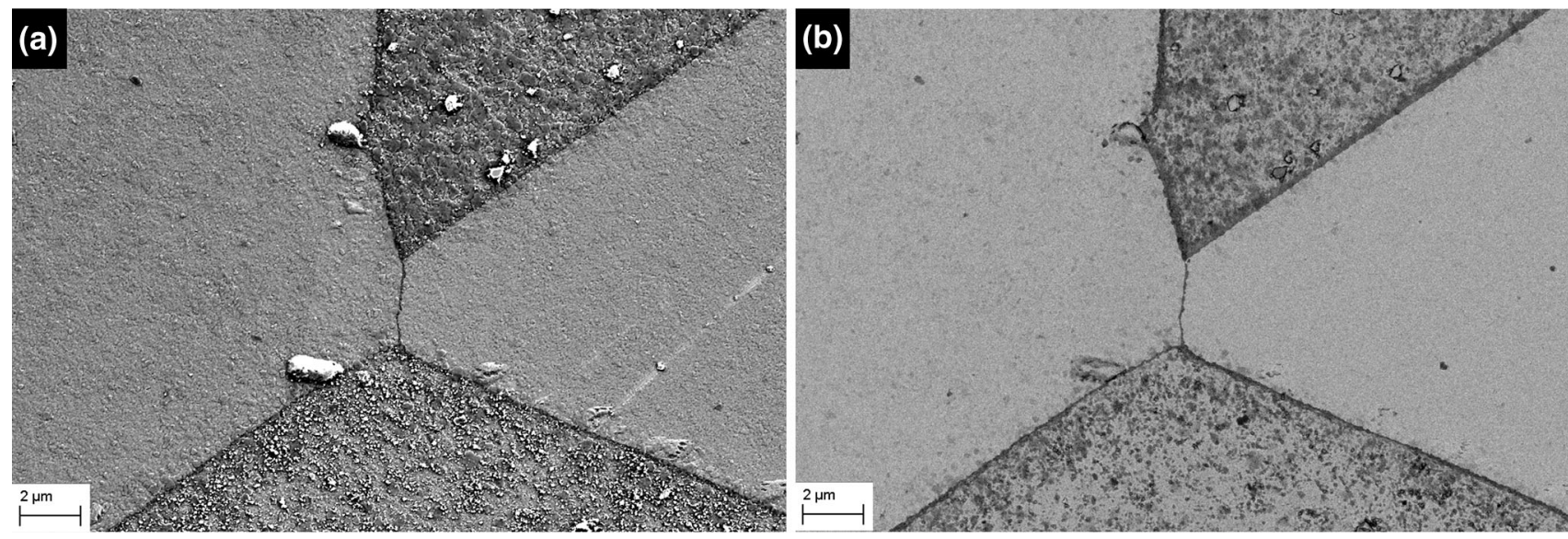

Fig. 1-(a) SE/BSE InLens and (b) BSE images of the oxidized surface morphology of Alloy 600SA sample A exposed to high-pressure steam at $400{ }^{\circ} \mathrm{C}$ for $500 \mathrm{~h}$ (sample A).
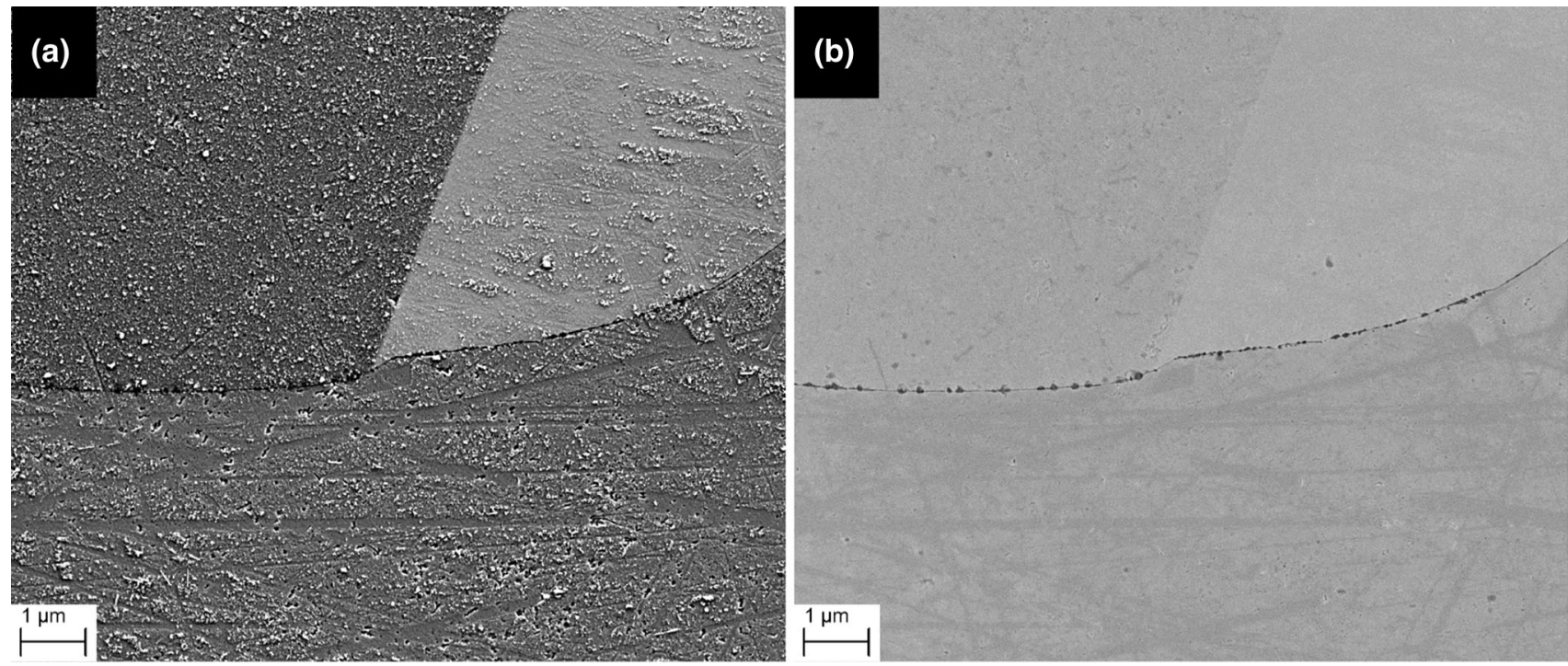

Fig. 2-(a) SE/BSE InLens and (b) BSE images of the oxidized surface morphology of Alloy 600SA specimens after PWR-simulated primary water exposure at $320^{\circ} \mathrm{C}$ for $1000 \mathrm{~h}$ (sample B).

Backscattered electron (BSE) imaging of sample A oxidized surface after the exposure to high-temperature steam at $400{ }^{\circ} \mathrm{C}$ (Figure 1(b)) suggested an orientation dependence for oxidation, consistent with other reports concerning crystallographic orientation effects on oxidation kinetics. ${ }^{[2,43]}$ BSE imaging also highlighted the presence of a marked darkly imaging GB network, which might be indication of the presence of an intergranular oxide. Using the InLens detector, which provides more topographic information due to the mixed SE and BSE signals, it was also possible to observe the presence of features both at the GBs and throughout the matrix (Figure 1(a)). These features were broadly similar to the surface Ni nodules observed on Alloy 600SA after exposure in low-pressure $\mathrm{H}_{2}$-steam environment at $480{ }^{\circ} \mathrm{C}$ and previously studied in detail by several laboratories. ${ }^{[25,26,32-34,43]}$ However, their density was much lower and the distribution appeared to be dependent on grain orientation.
The surface of sample B tested at $320{ }^{\circ} \mathrm{C}$ in high-temperature water exhibited a similar appearance. The surface appeared oxide-free, as observed from the InLens and BSE images (Figures 2(a) and (b)); furthermore, a darkly imaging GB network was evident along the entire surface (Figure 2(b)). In contrast to the material exposed in hydrogenated-steam, no surface nodules were observed at grain boundaries or within the matrix after the exposure in high-temperature water.

Additional BSE images of several GBs tested in both environments are shown in Figure $3\left(400{ }^{\circ} \mathrm{C}\right)$ and 4 $\left(320^{\circ} \mathrm{C}\right)$. In these BSE images, the presence of a pronounced dark contrast in the GB regions (indicating lower atomic number or density) is evident, which is consistent with the presence of an intergranular oxide. The main difference between the two samples was that the darkly imaging GB features (subsequently confirmed to be $\mathrm{Cr}_{2} \mathrm{O}_{3}$ via analytical electron microscopy/selected area electron diffraction) were slightly thicker for the 

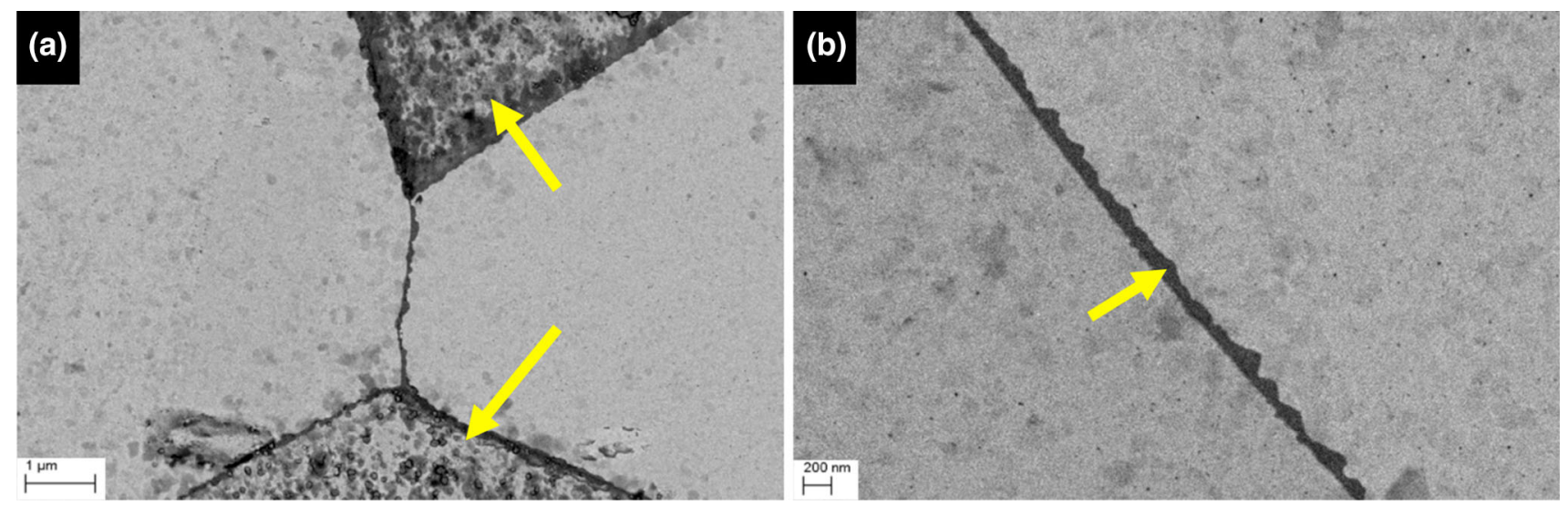

Fig. 3-BSE images of Alloy 600SA GBs in Sample A after exposure in high-pressure steam at $400{ }^{\circ} \mathrm{C}$ for $500 \mathrm{~h}$ showing (a) the grain-to-grain oxidation variations (arrows); (b) the "undulated" GB appearance (arrow).
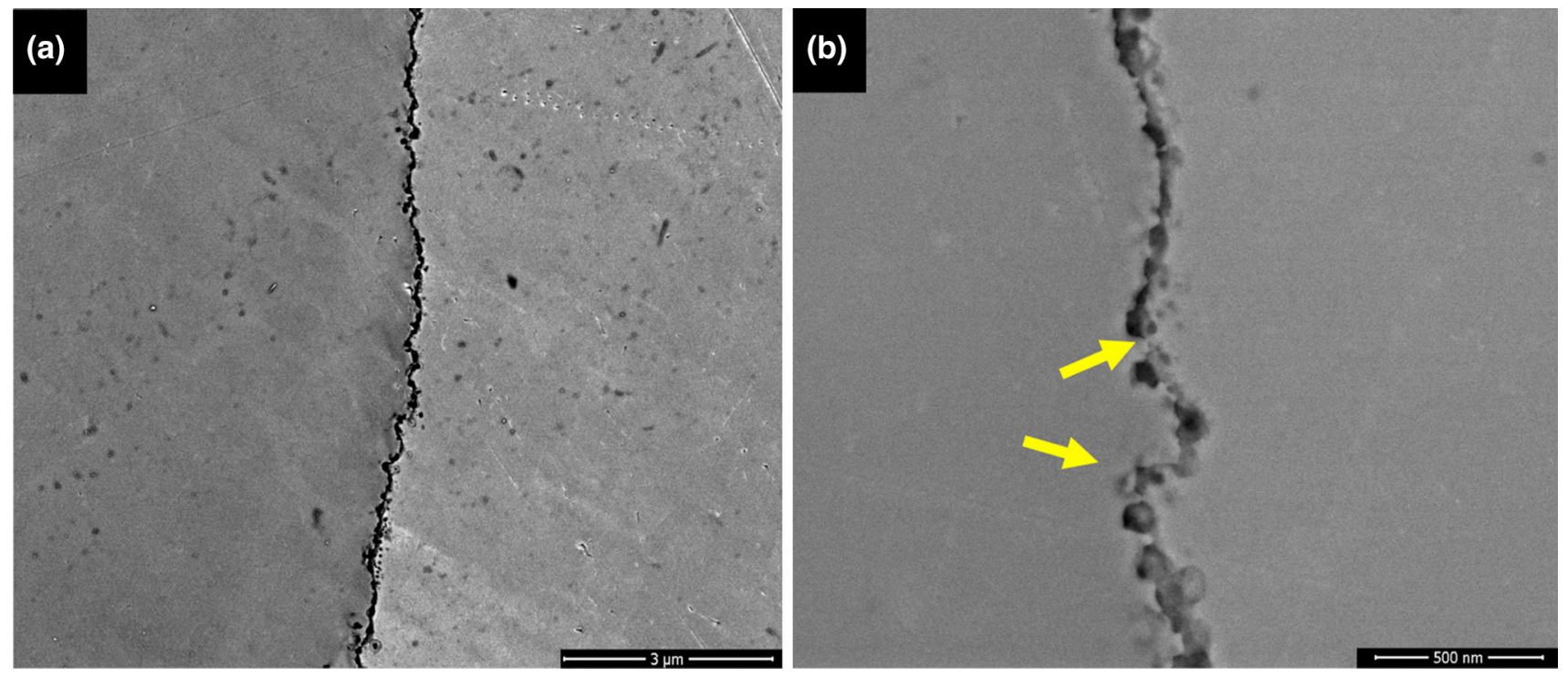

Fig. $4-(a, b)$ BSE images of Alloy 600SA GBs in sample B after exposure in PWR-simulated primary water at $320^{\circ} \mathrm{C}$ for $1000 \mathrm{~h}$ showing the "undulated" GB appearance (arrows).

coupons exposed in high-temperature steam $(\sim 100 \mathrm{~nm}$ as shown in Figure 3(b)) compared to those specimens tested in simulated primary water $(\sim 20 \mathrm{~nm}$ Figure $4(\mathrm{~b}))$. An important similarity was that the GBs in samples A and $\mathrm{B}$ exposed to $400{ }^{\circ} \mathrm{C}$ steam and $320^{\circ} \mathrm{C}$ water, respectively, were not straight, but had a bulged appearance with undulations several tens of $\mathrm{nm}$ in extent, as visible in Figures 3(b) and 4(b).

\section{B. Characterization of Oxidized GB Cross-Section FIB Specimens}

In order to determine whether PIO penetration occurred beneath the surface during the elevated temperature exposure in both environments (simulated primary water and high-temperature steam), several GBs were cross-sectioned using the FIB technique and analyzed using the SE and BSE imaging modes. Incoherent and coherent twin boundaries (e.g., $\Sigma 3$ ) were avoided since they are known to have low susceptibility to PIO and SCC. ${ }^{[44,45]}$ The representative GB cross-sections for the two exposures conditions (high-temperature steam (A) and high-temperature water (B)) are shown in Figures 5 and 6, respectively.

After the $400{ }^{\circ} \mathrm{C}$ high-temperature steam exposure of sample A, numerous GBs exhibited an undulated appearance on the surface (Figure 3(b)); these were subsequently cross-sectioned using the FIB and analyzed. A representative BSE image is shown in Figure 5. Specifically, the Alloy 600SA sample A was characterized by the presence of a darkly imaging surface layer, which appeared thicker on one grain (right) than the other (left). While this oxide appeared to be continuous and protective, it did not prevent the formation of an intergranular darkly imaging penetration (subsequently confirmed to be $\mathrm{Cr}_{2} \mathrm{O}_{3}$ via analytical electron microscopy, Section III-C) that proceeded for more than 500 $\mathrm{nm}$ along the GB (Figure 5). The GB region beneath the 


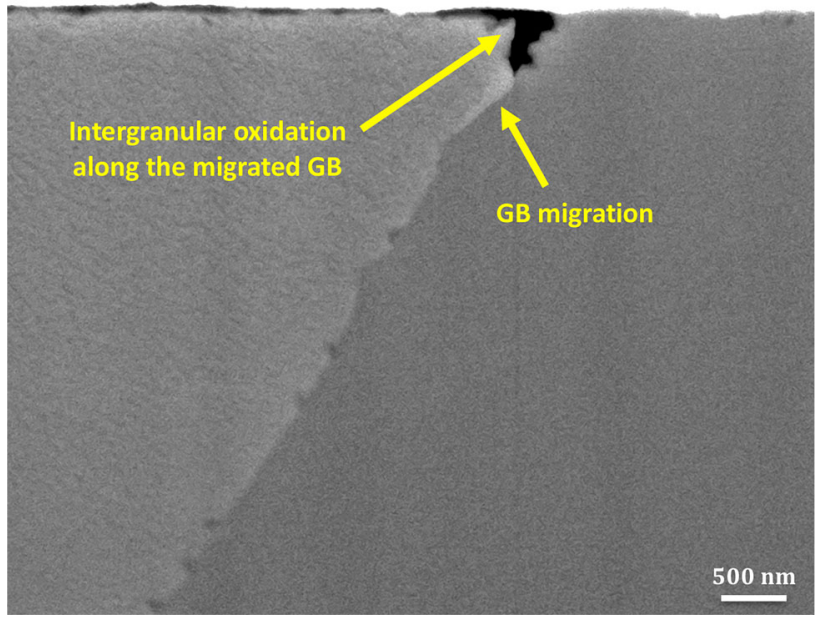

Fig. 5-BSE image of a sample A cross-section obtained through a GB after exposure to high-pressure steam at $400{ }^{\circ} \mathrm{C}$ for $500 \mathrm{~h}$, containing a small intergranular penetration consistent with oxide (yellow arrow) (Color figure online).

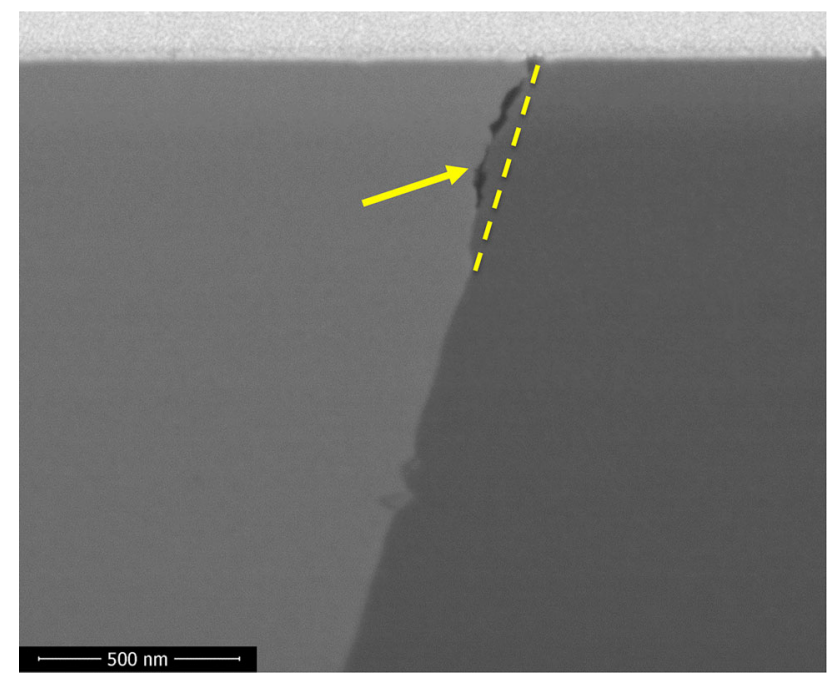

Fig. 6-BSE image of a sample B cross-section obtained through an oxidized GB after exposure to PWR-simulated primary water at $320{ }^{\circ} \mathrm{C}$, showing the darkly imaging penetration (yellow arrow) and GB undulation (Color figure online)

darkly imaging intergranular penetration was slightly bowed with the left grain protruding into the right grain. From the BSE image it was also observed that the bowed region appeared slightly brighter, which could suggest local changes in composition in element with higher atomic number ( $\mathrm{Ni}$ in the present case) as observed by Bertali et al. ${ }^{[30]}$

A representative BSE image of a FIB cross-section prepared from the Alloy 600SA sample B tested in simulated primary water at $320{ }^{\circ} \mathrm{C}$ is presented in Figure 6. In contrast to what was observed for the material tested at $400{ }^{\circ} \mathrm{C}$, no significant darkly imaging surface layer was detected for any of the analyzed GBs (Figure 6). Based on the detailed analysis of all FIB cross-section samples, no discrete darkly imaging particles (consistent with oxides) were detected beneath the surface. For the material tested in water at $320^{\circ} \mathrm{C}$ (sample B), a darkly imaging intergranular feature that penetrated the GB for more than $500 \mathrm{~nm}$ (Figure 6) was observed. This intergranular penetration appeared to be continuous although the analysis resolution was not sufficient to confirm it. The GB also appeared slightly undulated. The penetration depth was measured by analyzing more than 15 different GBs cross-sections for each oxidation temperature. The average penetration depth was approximately $800 \mathrm{~nm}$ for sample A oxidized at $400{ }^{\circ} \mathrm{C}$ and $500 \mathrm{~nm}$ for sample B oxidized at $320{ }^{\circ} \mathrm{C}$, thus confirming the increased PIO susceptibility at the higher temperature.

\section{Analytical Electron Microscopy Analysis of FIB Cross-Section Specimens}

Bright-field (BF) TEM, selected area electron diffraction (SAD), centered dark-field (DF) TEM, and STEM-EDX techniques were used to characterize the "bowed" GBs to confirm whether these regions had experienced GB migration during the exposure in high-temperature steam at $400{ }^{\circ} \mathrm{C}$ (sample A) and to identify the presence of oxides. A representative brightfield TEM image of one of the analyzed GBs extracted from the Alloy 600 coupons is shown in Figure 7.

The analysis focused on a bowed GB region just beneath the surface, in which the left grain extended over $200 \mathrm{~nm}$ into the right grain. This suggests that GB migration occurred during oxidation in the steam environment. However, the microstructural evidence that the GB migrated during the exposure in high-temperature steam was obtained from TEM analysis. Bright-field and centered dark-field TEM images (Figure 8(a)) showed the presence of the fine discrete $\mathrm{M}_{23} \mathrm{C}_{6}$ carbides, identified by selected area electron diffraction, along the GB beneath the migrated boundary with five small $\mathrm{M}_{23} \mathrm{C}_{6}$ carbides located along the original GB location to the left of the bowed GB plane. This confirmed that these fine carbides were present along the original location of the GB before migration occurred (Figure 8(b)).

The same GBs that exhibited the local migration were evaluated using analytical transmission electron microscopy. STEM-EDX spectrum imaging was used to characterize the local compositional variation in the migrated region as well as identify the darkly imaging regions observed in BSE images (Figure 5) as intergranular oxide. A series of Talos STEM-EDX spectrum image datasets showed that the surface oxide was enriched in both $\mathrm{Cr}$ and $\mathrm{Fe}$ as shown in the $\mathrm{O} \mathrm{K} \alpha, \mathrm{Cr}$ $\mathrm{K} \alpha$ (blue), and $\mathrm{Fe} \mathrm{K} \alpha$ (red) EDX elemental images in Figure 9. The presence of both $\mathrm{Fe}$ and $\mathrm{Cr}$ in the surface oxide is consistent with the typical chromite-type spinel oxide.

STEM-EDX characterisation of the "bowed" migrated GB region revealed a marked $\mathrm{Cr}$ and $\mathrm{Fe}$ depletion and a strong enrichment in the Ni. Higher magnification STEM-EDX elemental images from the same intergranular oxide showed that this oxide was primarily $\mathrm{Cr}$-rich and contained enrichments of $\mathrm{Ti}$ and $\mathrm{Al}$ oxide at the migrated GB ahead of the $\mathrm{Cr}$-rich oxide, 
Figure 10. Analysis of selected area electron diffraction patterns of the intergranular oxide was consistent with the presence of $\mathrm{Cr}_{2} \mathrm{O}_{3}, \mathrm{TiO}_{2}$, and $\mathrm{Al}_{2} \mathrm{O}_{3}$.

STEM-EDX elemental images revealed the presence of non-continuous surface intragranular oxide that formed within the grains away from the GB (Figure 11). Background-subtracted $\mathrm{Cr} \mathrm{K} \alpha, \mathrm{Fe} \mathrm{K} \alpha$ and $\mathrm{O} \mathrm{K} \alpha$ elemental images obtained from different areas along the external oxide revealed that the darkly imaging surface oxide was a mixed $\mathrm{Cr}$ - and Fe-rich oxide. Beneath the surface oxide a marked $\mathrm{Cr}$ and $\mathrm{Fe}$ depletion $(\sim 5 \mathrm{~nm})$ associated with $\mathrm{Ni}$ enrichment was observed. Although the surface oxide appeared continuous, it did not hinder the formation of subsurface Cr-rich discrete and interconnected internal oxide particles, which were most probably related to the presence of surface/near-surface defects such as dislocations, which might be induced by surface preparation.

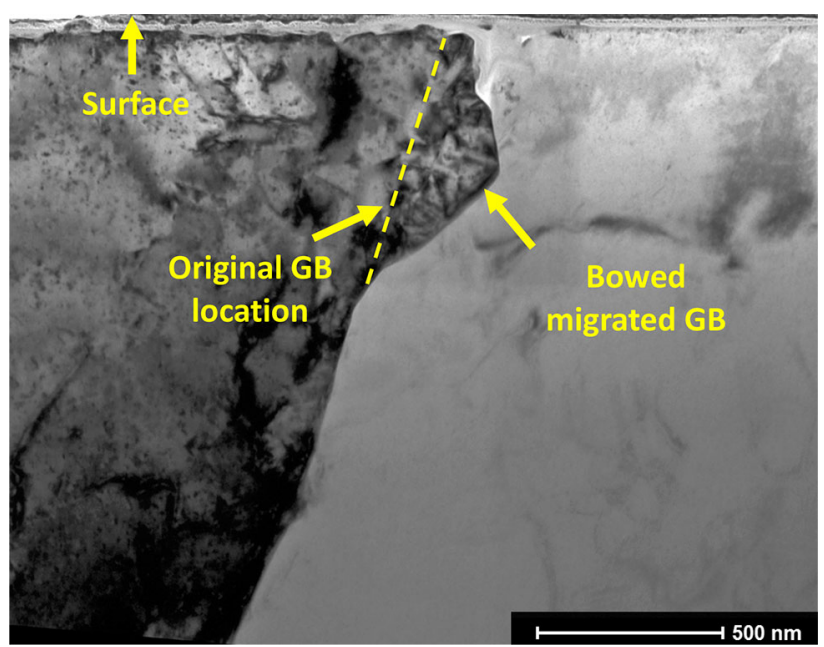

Fig. 7-TEM bright-field (BF) image showing the migrated GB (yellow arrow) (left grain is strongly diffracting) after exposure at $400{ }^{\circ} \mathrm{C}$ to high-pressure steam (sample A) (Color figure online).
Several cross-section samples, each containing one a $\mathrm{GB}$, were extracted from the oxidized sample B tested in PWR-simulated primary water at $320^{\circ} \mathrm{C}$ and characterized using STEM-EDX microanalysis. The $\mathrm{Cr}$ and $\mathrm{O}$ $\mathrm{K} \alpha$ elemental images of Figure 12 indicated that the intergranular oxide was mainly a $\mathrm{Cr}$-rich oxide. Along and ahead of the intergranular $\mathrm{Cr}$-rich oxide, some localized and asymmetric Ni enrichments were observed (Ni K $\alpha$ elemental image of Figure 12), which may be an indication of local GB migration due to the intergranular oxide formation.

Higher magnification STEM-EDX SI characterization of the same GB at the intergranular oxide "tip" revealed asymmetric $\mathrm{Cr}$ and $\mathrm{Fe}$ depletions and the $\mathrm{Ni}$ enrichment, as shown in Figure 13. The Ti K $\alpha$ elemental image (Figure 13) indicated a detectable Ti enrichment at the Cr-rich oxide tip, which suggests the possible presence of a Ti-rich oxide. Ahead of the preferential intergranular $\mathrm{Cr}$-rich oxide tip 4 fine $\mathrm{M}_{23} \mathrm{C}_{6}$ carbides were observed on the GB. This is clearly visible from the elemental images presented in Figure 12; the $\mathrm{Cr} \mathrm{K} \alpha$ image shows 4 discrete $\mathrm{Cr}$-rich precipitates, with no increase in the $\mathrm{O} \mathrm{K} \alpha$ signal, thereby indicating that these carbides were not oxidized. Furthermore, the slight depletion in $\mathrm{Cr}$ observed in Figure 13 ahead of the oxide is most likely related to the $\mathrm{Cr}$ depletion that accompanied precipitation of the $\mathrm{M}_{23} \mathrm{C}_{6}$ carbides during the water-quench.

\section{DISCUSSION}

In the present study, solution-annealed Alloy 600 was exposed to $400{ }^{\circ} \mathrm{C}$ high-temperature/high-pressure steam (A) and to $320^{\circ} \mathrm{C}$ simulated primary water (B) in the reducing side of the thermodynamic $\mathrm{Ni} / \mathrm{NiO}$ transition using a $\mathrm{H}_{2}$ addition to the water or steam phase. The main reason for maintaining these conditions (i.e., more reducing than the $\mathrm{Ni} / \mathrm{NiO}$ transition) was to be representative of the reducing conditions during operation of a PWR. It is well known ${ }^{[12,38,39]}$ that Alloy
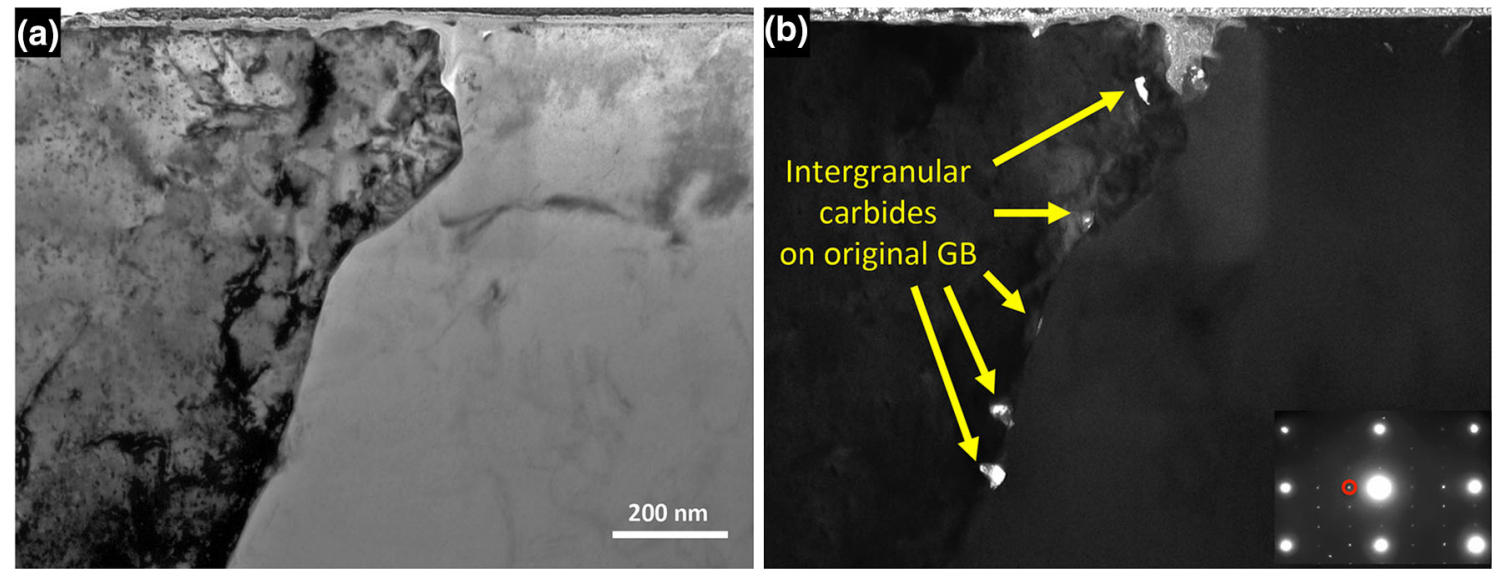

Fig. 8- (a) BF and (b) corresponding DF TEM images of the "bowed" (migrated) region at the GB after $500 \mathrm{~h}$ exposure at $400{ }^{\circ} \mathrm{C}$ high-pressure steam. The presence of intergranular $\mathrm{M}_{23} \mathrm{C}_{6}$ carbides along the path of the original GB (yellow arrows) confirmed the identification of the original GB position before migration. selected area electron diffraction patter in (b) showed the "cube-cube" orientation relationship between the face-centered cubic carbides and the face-centered cubic matrix (Color figure online). 


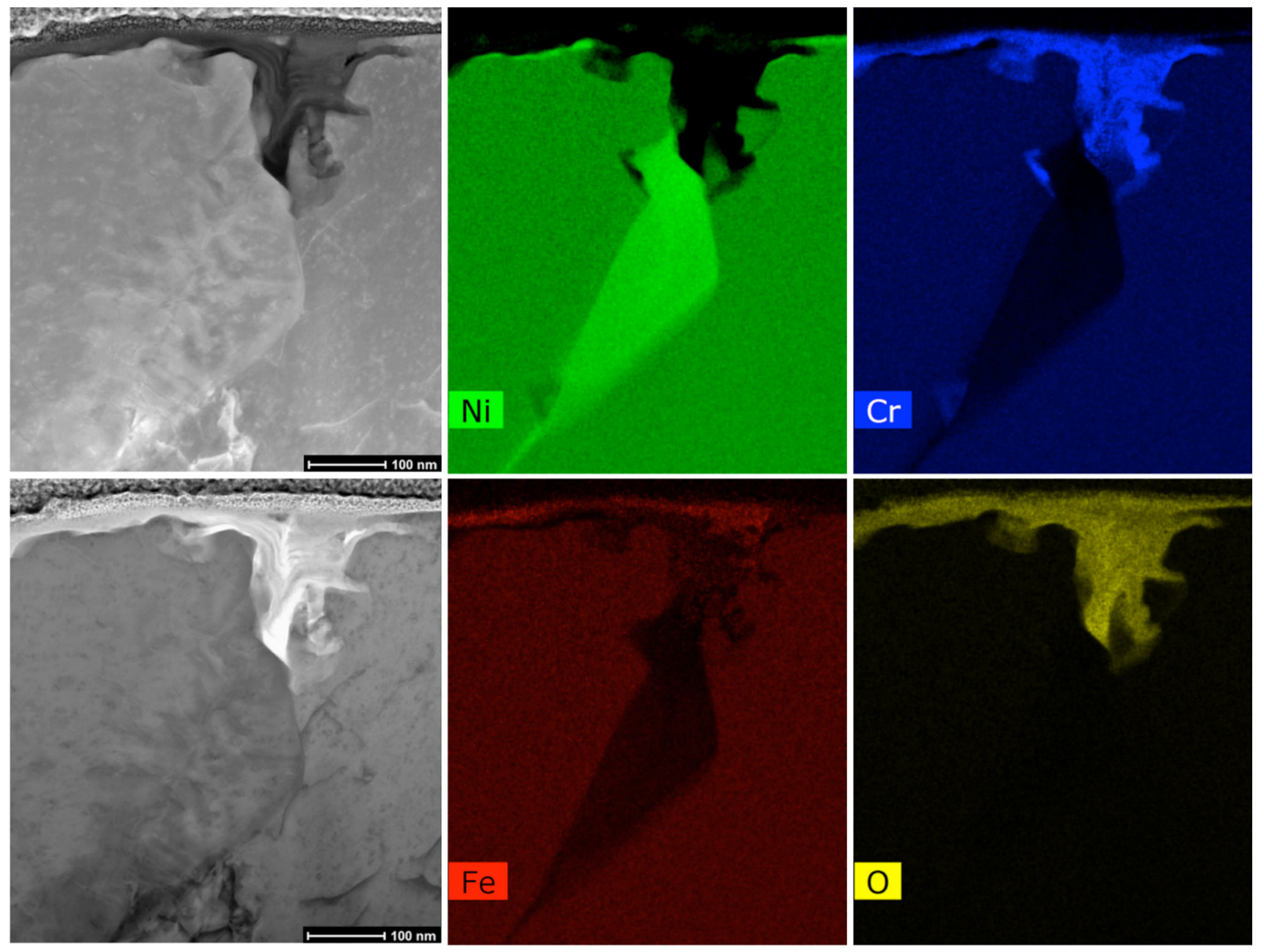

Fig. 9- HAADF and BF STEM images and corresponding STEM-EDX elemental images (Ni K, Cr K, Fe K, and O K) of the migrated GB after exposure at $400{ }^{\circ} \mathrm{C}$ to super-heated steam (sample A), showing the presence of a surface $\mathrm{Cr}$-Fe-rich oxide above the GB. Pronounced $\mathrm{Cr}$ and $\mathrm{Fe}$ depletions associated with a marked $\mathrm{Ni}$ enrichment are visible below the oxide layer in the migrated region.

600 IGSCC initiation susceptibility is greatest in proximity of the $\mathrm{Ni} / \mathrm{NiO}$ region, then suddenly drops under oxidizing conditions whereas it remains high in more reducing environments with dissolved hydrogen in excess of $60 \mathrm{cc} / \mathrm{kg}(\sim 5.5 \mathrm{ppm}) \cdot{ }^{[37]}$ In the present work, the environment was maintained in the $\mathrm{Ni}$ stability region but nonetheless close to the $\mathrm{Ni} / \mathrm{NiO}$ transition where the initiation susceptibility is still high. ${ }^{[37]}$ Also, the previous work by the present authors in low-pressure $\mathrm{H}_{2}$-steam environment at $480{ }^{\circ} \mathrm{C},{ }^{[32-34,43]}$ was performed under comparable oxidizing conditions with respect to the $\mathrm{Ni} / \mathrm{NiO}$ transition.

\section{A. Alloy 600 Intergranular Oxide Morphology}

The Scott and Le Calvar "internal oxidation" model ${ }^{[16,17]}$ was proposed to explain the well-known susceptibility of Alloy 600 to SCC initiation and propagation in PWR environment. ${ }^{[46,47]}$ The results of detailed microstructural studies ${ }^{[25,30,33,43]}$ have led to the more refined description of this mechanism as "preferential intergranular oxidation" since it is this latter process that is associated with the susceptibility. ${ }^{[24,27,30,32-34,43]}$ In fact, recent results highlighted that a continuous intergranular oxide is formed at GBs rather than discrete oxide particles, which are typical of the internal oxidation mechanism. Internal oxidation is usually a term for subsurface precipitation of solute-oxide particles that are not interconnected. ${ }^{[48]}$

The detailed microstructural analyses using FEGSEM imaging techniques, FIB cross-sections and TEM/ STEM-EDX analyses performed in this study of the oxidation behavior of sample A exposed to high-pressure hydrogenated-steam at $400{ }^{\circ} \mathrm{C}$ and PWR-simulated primary water at $320^{\circ} \mathrm{C}$ (sample B) showed a pronounced susceptibility of the alloy to PIO and highlighted strong similarities between the two environments. The detailed SEM and TEM/STEM-EDX characterization of Alloy 600SA after the exposure to high-pressure hydrogenated-steam at $400{ }^{\circ} \mathrm{C}$ and PWR primary water at $320{ }^{\circ} \mathrm{C}$ revealed notable changes at the surface and in the near-surface region of GBs. BSE images of the oxidized coupon surface suggested that every GB examined after the exposure in both environments contained a darkly imaging feature extending along the boundary, 


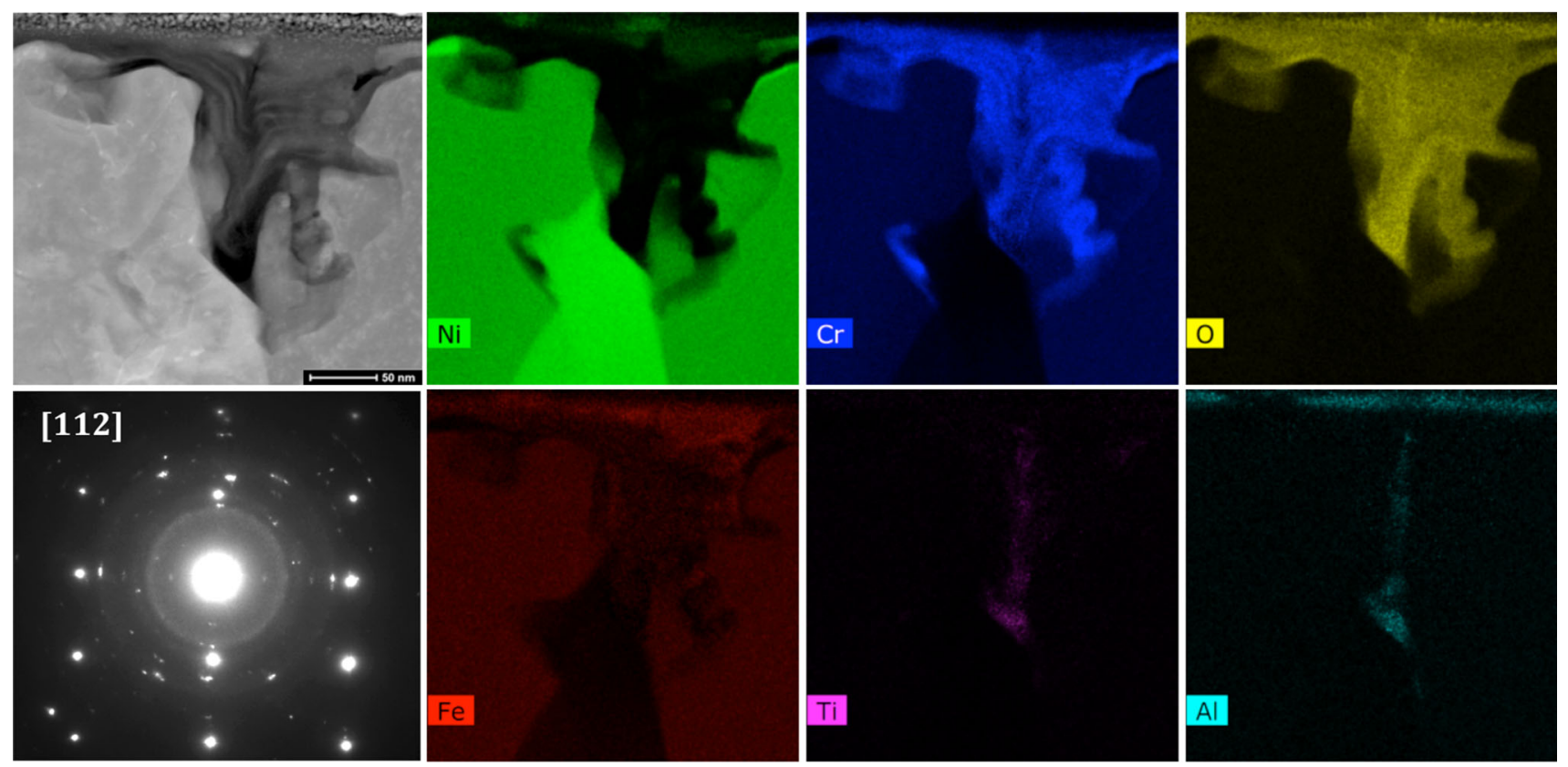

Fig. 10-HAADF STEM image and corresponding STEM-EDX elemental images of PIO/GB regions and [112] selected area electron diffraction pattern of the matrix and intergranular oxides in sample $\mathrm{A}$. The intergranular penetration consisted mainly of Cr-rich oxide with some Ti and $\mathrm{Al}$ enrichment in the central region and a coarser $\mathrm{Al} / \mathrm{Ti}$-rich oxide just ahead the $\mathrm{Cr}_{2} \mathrm{O}_{3}$. The apparent $\mathrm{Al}$ enrichment at the surface is due to the $\mathrm{Pt}$ and $\mathrm{Al}$ peak overlap. Analysis of the selected area electron diffraction pattern confirmed the presence of $\mathrm{Cr}_{2} \mathrm{O}_{3}$; electron diffraction data were also consistent with the presence of $\mathrm{TiO}$ and $\mathrm{Al}_{2} \mathrm{O}_{3}$.
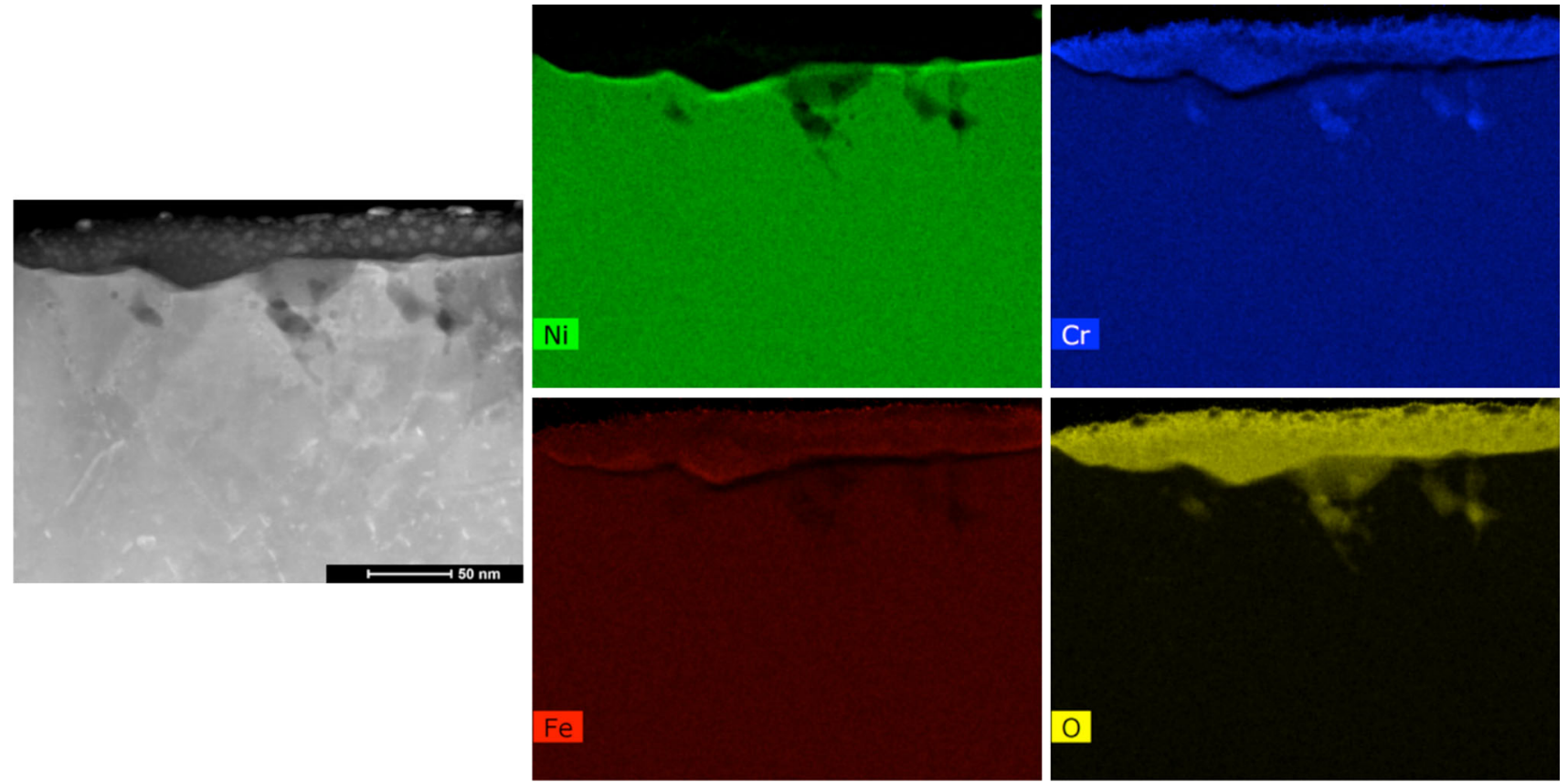

Fig. 11-HAADF STEM image and corresponding STEM-EDX elemental images of the $\mathrm{Cr}$ - and Fe-rich oxide and discrete Cr-rich internal oxide particles formed in Alloy 600 (sample A) during exposure in high-pressure steam at $400{ }^{\circ} \mathrm{C}$.

(Figures 1, 2, 3, and 4) SEM evaluation of the FIB cross-section samples extracted from the high-pressure steam and PWR primary water specimens revealed that the darkly imaging feature penetrated along the GBs for several hundreds of nanometers (Figures 5 and 6). The average penetration depth was approximately $800 \mathrm{~nm}$ for the material tested in high-pressure hydrogenated-steam at $400{ }^{\circ} \mathrm{C}$ (sample A) and $500 \mathrm{~nm}$ for the material tested in PWR primary water at $320^{\circ} \mathrm{C}$ (sample B). STEM-EDX microanalyses and TEM/ selected area electron diffraction confirmed that the darkly imaging penetration along the GBs was intergranular $\mathrm{Cr}_{2} \mathrm{O}_{3}$ oxide that formed during high-temperature exposure in high-pressure steam and during PWR 

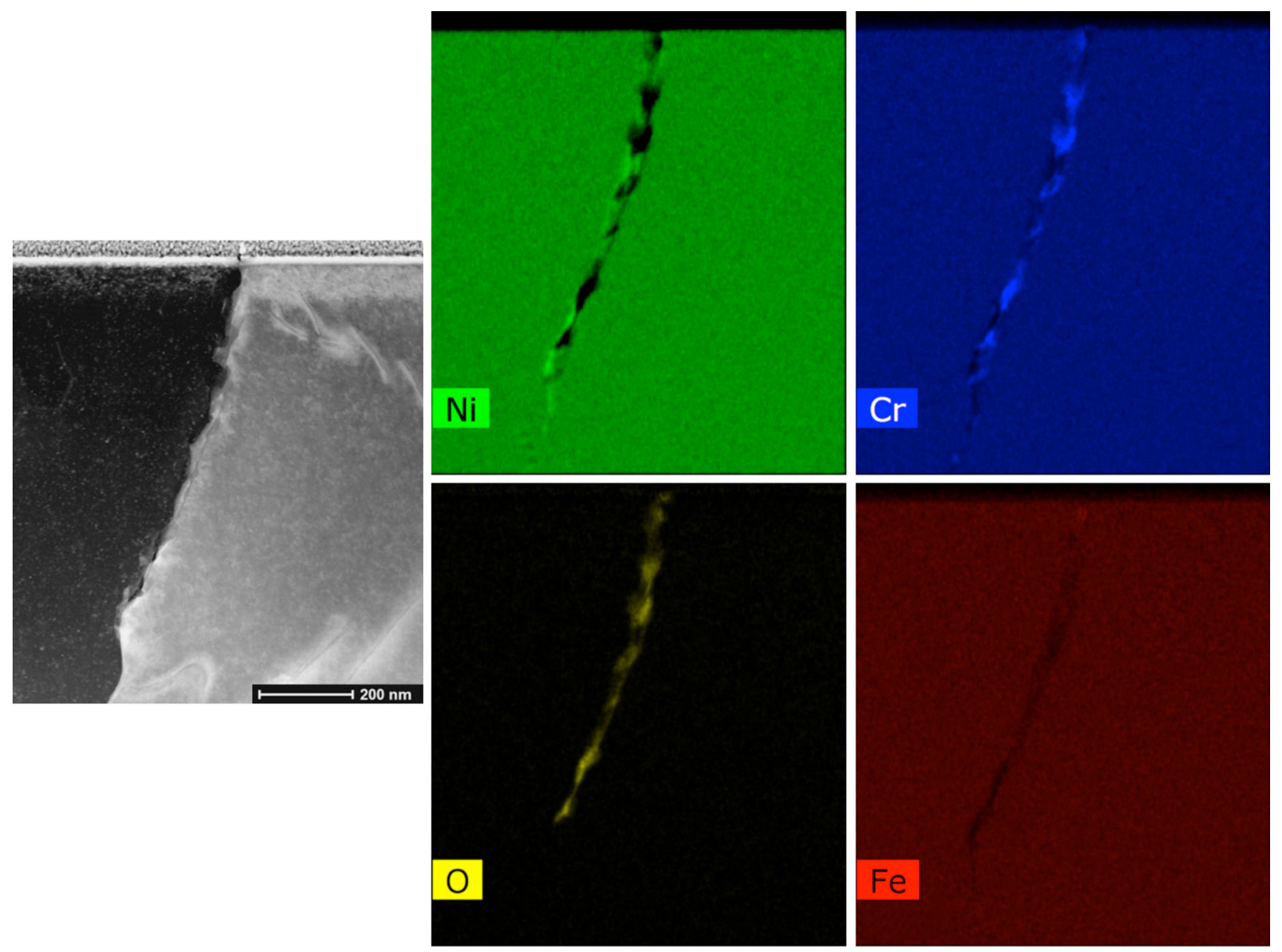

Fig. 12-Talos STEM-HAADF image and corresponding STEM-EDX elemental images of the PIO in sample B that occurred during exposure in PWR-simulated primary water at $320^{\circ} \mathrm{C}$. The intergranular oxide is Cr-rich.

primary water exposure. Additionally, STEM-EDX spectrum imaging of several GBs regions revealed that the intergranular $\mathrm{Cr}_{2} \mathrm{O}_{3}$ oxide also contained a discrete nano-scale Al- and Ti-rich oxide (Figures 9, 10, 11, 12, and 13) that was identified via electron diffraction to be $\mathrm{Al}_{2} \mathrm{O}_{3}$ and $\mathrm{TiO}_{2}$. The $\mathrm{Ti}$ and $\mathrm{Al} \mathrm{GB}$ enrichments and subsequent oxide formation, which is thermodynamically expected, are the result of $\mathrm{Ti}$ and $\mathrm{Al}$ diffusing to and along the GBs during the elevated temperature environmental exposure. The formation of intergranular $\mathrm{Cr}, \mathrm{Ti}$ and $\mathrm{Al}$ oxides have also been independently observed by several groups ${ }^{[14,32,43]}$ on Alloy 600SA tested in low-pressure $\mathrm{H}_{2}$-steam environment at $480{ }^{\circ} \mathrm{C}$, and by Persaud et al..$^{[49]}$ on Alloy 600 tested in PWR-simulated primary water at $320{ }^{\circ} \mathrm{C}$. The results of these analyses suggested that the mechanism by which the intergranular oxide forms is similar if not the same in the two different environments despite the considerable temperature and fluid density differences. The idea that the same oxidation mechanism is active in both high-pressure steam at $400^{\circ} \mathrm{C}$ (sample A) and PWR primary water at $320^{\circ} \mathrm{C}$ (sample B) is also strongly supported by previous findings from Economy et al., ${ }^{12]}$ who observed that that Alloy 600 fracture surfaces showed marked similarities between PWR primary water and high-pressure steam.

Previous studies on the same Alloy 600SA material tested in low-pressure $\mathrm{H}_{2}$-steam environment at $480{ }^{\circ} \mathrm{C}$ showed that the oxide morphology and composition was very similar to what was observed in this study. ${ }^{[30,43]}$ The intergranular oxide that formed at $480{ }^{\circ} \mathrm{C}$ was primarily composed of $\mathrm{Cr}_{2} \mathrm{O}_{3}$ but also contained a discrete nano-scale $\mathrm{Al}_{2} \mathrm{O}_{3} / \mathrm{TiO}_{2}$ "core" within the $\mathrm{Cr}_{2} \mathrm{O}_{3}$ and near the termination of the $\mathrm{Cr}_{2} \mathrm{O}_{3}$ penetration. These strong similarities amongst the different environments indicates that the PIO mechanism can be extended over the temperature range from $320^{\circ} \mathrm{C}$ up to $480{ }^{\circ} \mathrm{C}$, and also provides evidence that the low-pressure $\mathrm{H}_{2}$-steam system employed by several laboratories ${ }^{[14,25,26,32-34,43]}$ can be used as a surrogate environment to accelerate the incubation time for SCC initiation without changing the degradation mechanism.

Another important finding was the marked $\mathrm{Cr}$ and $\mathrm{Fe}$ depletion and $\mathrm{Ni}$ enrichment observed in the vicinity of the oxidized Alloy 600SA GBs for both the exposures in PWR primary water and in high-pressure hydrogenated-steam. The $\mathrm{Cr}$ - and Fe-depleted regions were always asymmetric (one grain only) and were associated 

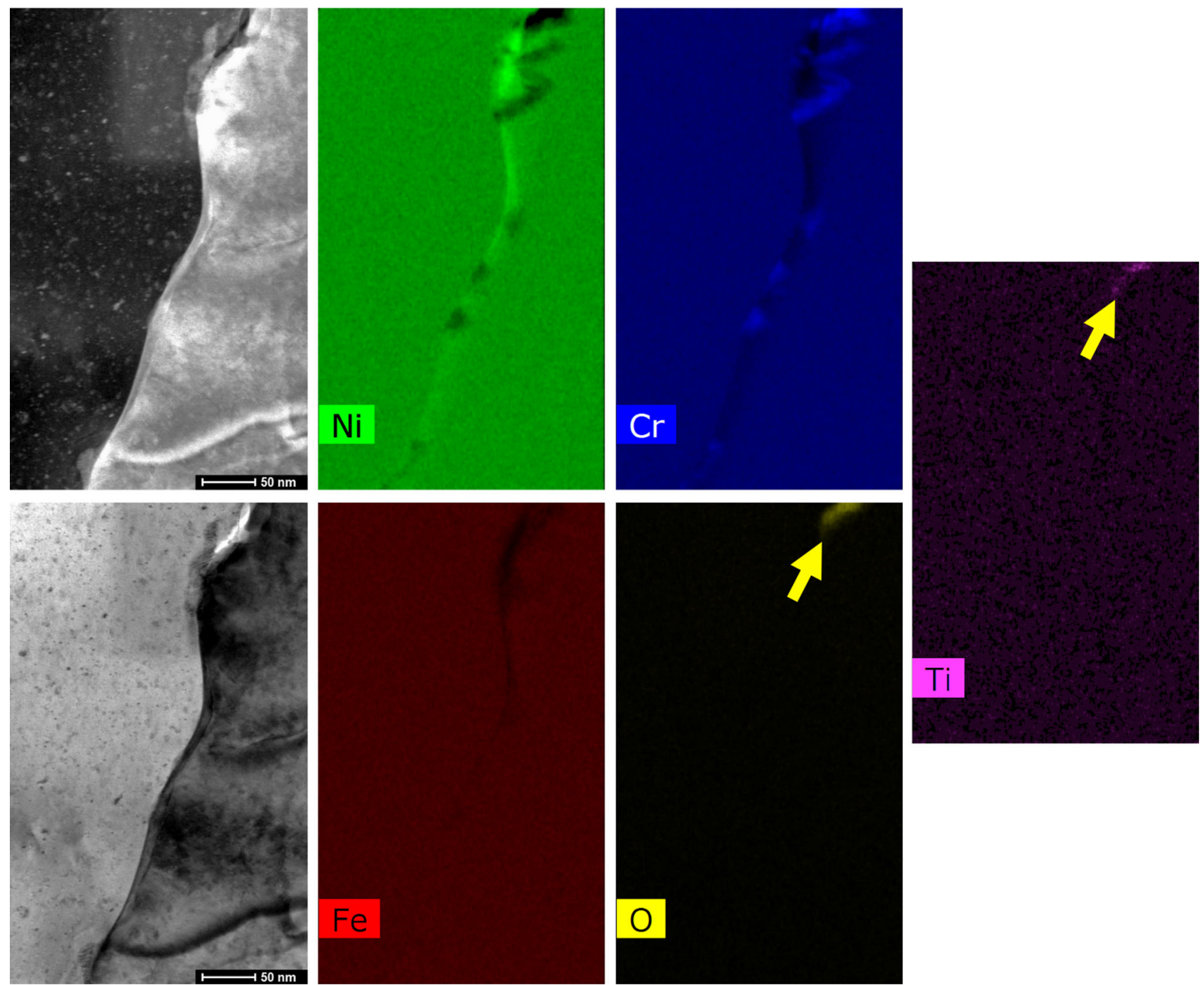

Fig. 13-HAADF and BF STEM images and corresponding STEM-EDX elemental images of the region ahead the Cr-rich oxide tip showing the localized $\mathrm{Ti}$ enrichment (arrowed) which can be superimposed to a slight $\mathrm{O}$ enrichment (arrowed) and the asymmetric $\mathrm{Cr}$ depletion and $\mathrm{Ni}$ enrichment formed during exposure in PWR-simulated primary water at $320^{\circ} \mathrm{C}$ (sample B).

with the formation of the intergranular oxide. These results are key findings suggesting the occurrence of GB migration during the exposure in high-pressure steam at $400{ }^{\circ} \mathrm{C}$ (sample A) and its possible occurrence in PWR primary water at $320{ }^{\circ} \mathrm{C}$ (sample B) and is discussed in details in the next section.

\section{B. "Precursor Events" to SCC: PIO and DIGM}

The localized migration of GBs in the near-surface region of the same Alloy 600SA material tested in low-pressure $\mathrm{H}_{2}$-steam environment at $480{ }^{\circ} \mathrm{C}$ was reported in 2013 to $2015 .^{[25,30,33]}$ These features were associated with GB migration and were considered to be important "precursors" to intergranular oxidation and SCC, ${ }^{[25,30,33]}$ although more work is required to understand their implication on the crack propagation regime.

Interestingly, sample A exposed to high-pressure hydrogenated-steam at $400{ }^{\circ} \mathrm{C}$ showed a marked susceptibility to GB migration, as shown in Section III-C. The occurrence of GB migration during oxidation in high-pressure hydrogenated-steam at $400{ }^{\circ} \mathrm{C}$ was confirmed by TEM observations of discrete $\mathrm{M}_{23} \mathrm{C}_{6}$ carbides that decorated the location of the original boundaries. These carbides formed despite water-quenching after the solution-annealing treatment of Alloy 600SA, and did not oxidize during the $400{ }^{\circ} \mathrm{C}$ steam exposure. These fine $\mathrm{M}_{23} \mathrm{C}_{6}$ were left behind when the grain boundaries migrated laterally, thereby acting as "markers" for the identification of the original boundary location. In order to prove that GB migration occurs during the exposure and is caused by the oxidation process, an extensive analysis of the baseline material is required to ensure that no undulated regions can be observed prior to exposure. Previous publications from the current authors ${ }^{[30]}$ clearly showed that no GB undulations were present before the exposure in the elevated temperature environment, and that the GBs did not migrate at the elevated temperature in an inert environment, thus confirming that GB migration occurred during oxidation in hydrogenated-steam. 


\section{Arrhenius}

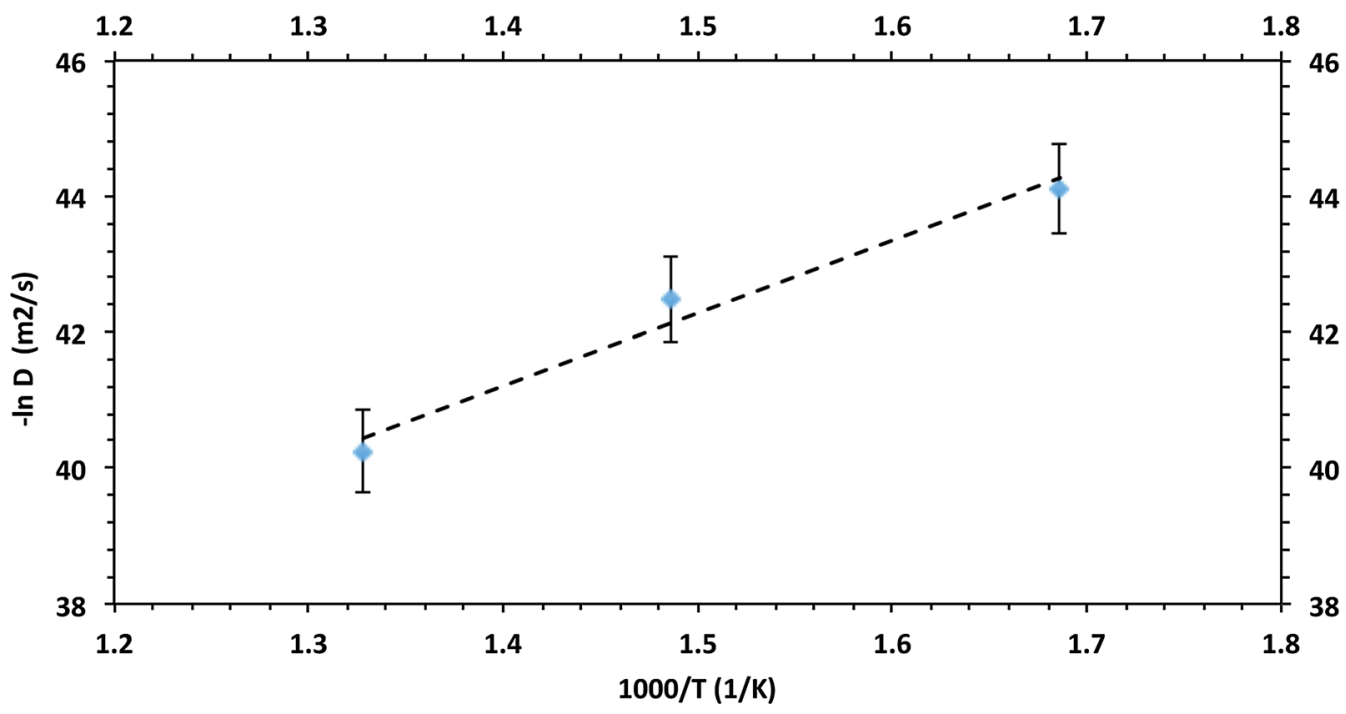

Fig. 14-Arrhenius plot of the intergranular oxide penetration depth showing a linear relationship between the intergranular Oxygen diffusion coefficient against $1 / \mathrm{T}$.

For the sample B exposed to PWR-simulated primary water at $320^{\circ} \mathrm{C}$ the asymmetric $\mathrm{Cr}$ depletion and $\mathrm{Ni}$ enrichment were still detectable at the GBs although on a notably reduced scale compared to that observed at higher temperature in the different environments. The narrower $\mathrm{Cr}$-depleted/Ni-enriched migrated region compared to those formed at higher temperatures can be explained by the reduction in lattice and GB solid-state diffusivities which are thermally activated processes. In the present case, at $320^{\circ} \mathrm{C}$ both substitutional and interstitial lattice diffusion are essentially negligible over laboratory timescales whereas the GB diffusivity is markedly lower than at higher temperature. Therefore, considering that the migration is associated with both lattice and GB diffusion, ${ }^{[30,50-52]}$ it is expected that the $\mathrm{GB}$ oxidation and migration rates are lower at $320{ }^{\circ} \mathrm{C}$ (A) than at $400{ }^{\circ} \mathrm{C}$ (B) or at higher temperatures $\left(480{ }^{\circ} \mathrm{C}\right)$. This trend is readily apparent when comparing the Alloy 600SA GB migrations observed at $400^{\circ} \mathrm{C}$ in high-pressure hydrogenated-steam (B) to those in the low-pressure $\mathrm{H}_{2}$-steam environment at $480{ }^{\circ} \mathrm{C}$ reported by Bertali et al. ${ }^{[30]}$ Moreover, other laboratories have reported the presence of an asymmetric $\mathrm{Ni}$-enriched region along oxidized GBs after exposure in PWR-simulated primary water at similar temperature to the one used in this study. ${ }^{[31,53]}$

STEM-EDX microanalysis of the migrated GBs showed that a $\mathrm{Cr}$ - and $\mathrm{Fe}$-rich oxide layer could readily form at the surface in the vicinity of the boundaries. The surface oxide formation is believed to be the main cause for the significant $\mathrm{Cr}$ - and $\mathrm{Fe}$-depleted region at the $\mathrm{GBs}$ and in the near-surface region. In fact, $\mathrm{Cr}$ and $\mathrm{Fe}$ diffusion is facilitated along the boundary due to the presence of vacancies and defects that are "frozen" in the bulk, especially at low temperatures (below $400{ }^{\circ} \mathrm{C}$ ). The increased diffusivity of the alloying elements along the GBs, and the compositional gradient between the depleted GB and the matrix of the adjacent (non-depleted) grain are thought to be the driving forces responsible for the GB migration phenomena. ${ }^{[50-52]}$ The migration process, which is termed "diffusion-induced grain boundary migration", has been extensively studied in the past for several binary alloys ${ }^{[50-52]}$ tested at high temperature. The mechanism is based on the observation that when solute atoms $(\mathrm{Cr}$ and $\mathrm{Fe})$ diffuse along the boundary out to the surface to form an oxide, the boundary is observed to move laterally, leaving behind a solute-depleted region. In Alloy 600SA the migrated $\mathrm{Cr}$ - and $\mathrm{Fe}$-depleted region may be characterized by the presence of large compressive or tensile stresses ${ }^{[52]}$ due to the differences of the fluxes and atomic dimensions of solute and solvent atoms. The presence of stresses in the migrated region can contribute to the fracture of the brittle surface and intergranular oxide, thus exposing the GB beneath to the environment promoting further intergranular oxidation. This mechanism can then be self-sustained, with repeated GB oxidation, migration and oxide fracture. Recent work ${ }^{[30]}$ has also shown that Alloy 600SA is susceptible to DIGM in low-pressure $\mathrm{H}_{2}$-steam environment at $480{ }^{\circ} \mathrm{C}$ and it was noted that this mechanism might play a fundamental role in the GB intergranular oxidation susceptibility and IGSCC initiation of Alloy 600.

The DIGM mechanism can also explain the higher resistance of Alloy 690 to PIO and IGSCC. Alloy 690 (with 30 wt pet $\mathrm{Cr}$ ) will form $\mathrm{Cr}_{2} \mathrm{O}_{3}$ rapidly, providing a protective surface oxide above the GBs without creating the pronounced compositional gradient. The less severe compositional gradient between the matrix and the Cr-depleted GB coupled with the reduced extent of GB migration may explain the lower PIO susceptibility of Alloy 690 . 
Although marked $\mathrm{Cr}$ and $\mathrm{Fe}$ depletions have been detected also for Alloy 600 tested at temperatures more relevant to PWR operational conditions, ${ }^{[31,53]}$ no definitive proof of the occurrence of GB migration (i.e., evidence of carbide "markers" at the original boundary location) had been provided. The results reported herein provide direct evidence for the occurrence of GB migration in sample A tested in high-pressure/high-temperature hydrogenated-steam at $400{ }^{\circ} \mathrm{C}$, thus extending the DIGM mechanism temperature range from $480{ }^{\circ} \mathrm{C}$ down to $400{ }^{\circ} \mathrm{C}$. Furthermore, the evidence of GB migration and the intergranular oxide formation in high-pressure hydrogenated-steam at $400{ }^{\circ} \mathrm{C}$ (B) were identical to those observed in low-pressure $\mathrm{H}_{2}$-steam at $480{ }^{\circ} \mathrm{C},{ }^{[30,43]}$ thus strongly indicating that the mechanism by which the intergranular oxide formed is identical for these two environments. These results suggest that the low-pressure $\mathrm{H}_{2}$-steam environment can be used as a surrogate environment to simulate the high-pressure hydrogenated-steam environment and to accelerate the kinetics of PIO and IGSCC initiation.

The variation in the bulk diffusivity between $\mathrm{H}_{2}$-steam environment at $480{ }^{\circ} \mathrm{C}$, high-pressure steam at $400{ }^{\circ} \mathrm{C}$ (sample A) and PWR primary water at $320^{\circ} \mathrm{C}$ (sample B) was confirmed by the STEM-EDX microanalyses performed in the vicinity of the oxidized coupon surface (away from grain boundaries). Previous research ${ }^{[43]}$ has shown the presence of classic ultrafine internal oxides extended $200 \mathrm{~nm}$ into the Alloy 600 matrix after exposure to the $\mathrm{H}_{2}$-steam environment at $480{ }^{\circ} \mathrm{C}$. At $400{ }^{\circ} \mathrm{C}$ (B) the maximum internal oxide penetration depth was in the range of few tens of nanometres (Figure 11) whereas at $320{ }^{\circ} \mathrm{C}$ (A) no internal Cr-rich oxide particles were detected via analytical electron microscopy. From these results the maximum bulk $\mathrm{O}$ diffusion coefficient (D) in Alloy 600 can be estimated by equating the typical depth of internal oxidation $(\mathrm{x})$ over the test time $(\mathrm{t})$ to $(\mathrm{Dt})^{0.5}$, which yields a value of $\sim 9.2 \times 10^{-20} \mathrm{~m}^{2} / \mathrm{s}$ at $480{ }^{\circ} \mathrm{C}$ and $\sim 5 \times 10^{-22} \mathrm{~m}^{2} / \mathrm{s}$ at $400{ }^{\circ} \mathrm{C}$. However, it was not possible to measure the bulk $\mathrm{O}$ diffusion coefficient at $320^{\circ} \mathrm{C}$ due to absence of measurable internal oxidation after 1000 hours of exposure. As expected, the GB diffusivity of $\mathrm{O}$ appeared to be affected by the reduction in temperature in a similar manner to the bulk diffusivity. Considering an average penetration depth of $1.1 \mu \mathrm{m}$ at $480{ }^{\circ} \mathrm{C}$ after 120 hours of exposure, ${ }^{[25,43]} 0.8 \mu \mathrm{m}$ at $400{ }^{\circ} \mathrm{C}$ after 500 hours (sample A), and of $0.5 \mu \mathrm{m}$ at $320^{\circ} \mathrm{C}$ after 1000 hours (sample B), the calculated GB diffusion coefficients for $\mathrm{O}$ are $3.3 \times 10^{-18}, 3.5 \times 10^{-19}$, and $7 \times 10^{-20} \mathrm{~m}^{2} / \mathrm{s}$, respectively. Based on these results, it is clear that the reduction in temperature markedly reduces both the bulk and GB diffusivities in Alloy 600, thereby explaining the reduced extent of GB migration observed as the temperature decreased from 480 to $320^{\circ} \mathrm{C}$. The reduction in GB diffusivity as a function of $\mathrm{T}$ is clearly visible when the logarithm of the diffusion coefficient is plotted against $1 / \mathrm{T}$, as shown in the graph presented in Figure 14. The graph also shows that preferential intergranular oxidation mechanism has a linear trend and follows an Arrhenius relationship with activation energy of $85 \mathrm{~kJ} / \mathrm{mol}$, which is similar to the activation energy calculated in the past for IGSCC initiation. ${ }^{[10]}$

It is also important to highlight that this calculated diffusion coefficient data for both bulk and GB diffusivities for $\mathrm{O}$ and $\mathrm{Cr}$ are in good agreement with the previous experimental data obtained on Alloy 600 tested in elevated temperature environments below $500{ }^{\circ} \mathrm{C} \cdot{ }^{[21,24,49]}$ However, the discrepancy between the experimentally measured lattice (bulk) and GB diffusion coefficients and data extrapolated from higher temperature oxidation studies ${ }^{[18,19]}$ is several orders of magnitude. This difference in diffusivities is most likely related to other factors that can enhance the $\mathrm{O}$ and $\mathrm{Cr}$ diffusivities in Alloy 600 as discussed below.

\section{Enhanced $G B$ and bulk diffusivities}

The presence of surface defects such as dislocations can enhance the diffusivity of substitutional elements, such as $\mathrm{Cr}$, and this argument has been used to explain the large surface sensitivity of Alloy 600 oxidized in high-temperature $\mathrm{H}_{2}$-steam. ${ }^{[26,43,54]}$ In the present case, a low density of surface defects was expected due to the careful polishing procedure employed during coupon preparation; nevertheless, it is impossible to eliminate all dislocations. These can be preferentially oxidized and provide a percolating path for the transition from external to internal oxidation. ${ }^{[5]}$ Therefore, once the subsurface oxidation process has initiated, the large volume increase caused by oxide formation can create large compressive stresses in the near-surface region that are balanced by a tensile stress in the matrix. This effect has been demonstrated using the FIB micro-hole drilling technique on Alloy 600 coupons oxidized in the $\mathrm{H}_{2}$-steam environment. ${ }^{[43]}$ Such compressive stresses could be released by a creep mechanism at high temperatures $\left(800{ }^{\circ} \mathrm{C}\right.$ or above) but not at the temperatures relevant for this work. It could be argued that at these low temperatures the generation of dislocations in the bulk could be responsible for the enhanced $\mathrm{O}$ diffusion, though this explanation seems implausible. A more probable possibility is that the incoherent interface between the internal oxide particles and the matrix acts as a short-circuit diffusion path and enhances $\mathrm{O}$ diffusion in the lattice as reported by Whittle et al. ${ }^{[56]}$ The GB diffusivity can also be enhanced by the presence of the incoherent oxide/metal interface at the GB. For example, high-temperature studies on $\mathrm{Ni}$-Al alloys ${ }^{[56]}$ revealed that the apparent $\mathrm{O}$ diffusion coefficient increased at $800{ }^{\circ} \mathrm{C}$ due to the presence of an incoherent and continuous oxide/matrix interface. In the case of Alloy 600 the observations revealing the presence of a Ti- and Al-rich oxide, which has been consistently detected at the oxidized grain boundaries in high-pressure hydrogenated-steam and high-temperature water (Figures 10 and 13), as well as in previous studies in low-pressure $\mathrm{H}_{2}$-steam, ${ }^{[30,32,43]}$ could act in a similar manner. It is possible that the formation of this intergranular $\mathrm{Ti}$ and $\mathrm{Al}$ oxide detected ahead of the $\mathrm{Cr}_{2} \mathrm{O}_{3}$ may be related to what has been described as "heat-to-heat variability" in the SCC susceptibility of 
Alloy 600. A second factor that can increase the GB diffusion coefficient is the generation of a tensile stress ahead of the intergranular oxide that is required to balances the compressive stress generated with volume expansion (Pilling-Bedworth effect). In fact, $\mathrm{GB} O$ diffusion is faster in Ni-base alloys subjected to tensile stress $^{[57,58]}$ as is the intergranular oxidation kinetics. ${ }^{[43]}$

Although the synergistic effect of these two accelerating factors could partially explain the enhanced $\mathrm{O}$ diffusivity observed in Alloy 600, the discrepancy between the experimentally measured and the extrapolated oxygen diffusivity is still too large (4 to 5 order of magnitude) so that the enhancement must be related to another factor: diffusion-induced GB migration. The DIGM mechanism and the ability of grain boundaries to migrate during the oxidation processes can explain the difference in the diffusivities. It has been reported that diffusion along moving boundaries is four orders of magnitude faster than for stationary boundaries, ${ }^{[59,60]}$ which is also the difference between the calculated $\mathrm{O}$ and $\mathrm{Cr}$ diffusion coefficients and those required to account for the measured SCC crack growth rates in Alloy $600 .^{[21,24,49]}$ It is therefore postulated that one of the most important factors for enhancing the PIO mechanism at a moving crack tip might be the ability of the boundary to migrate. Once a crack is formed, the crack tip can be subjected to high level of tensile stresses, which can additionally increase the oxygen diffusivity and intergranular oxide penetration leading to a faster crack propagation rate. ${ }^{[43]}$ The synergistic effect of these two factors is considered to be the reason by which Alloy 600 IGSCC is extremely rapid in PWR primary water, with the DIGM mechanism being more important during crack initiation, and the stress-assisted diffusion mechanism being more prominent during propagation. This hypothesis is also supported by the similar results obtained by Sennour et al. ${ }^{[53]}$ on Alloy 600 SCC specimens. They observed a marked asymmetric $\mathrm{Cr}$ and $\mathrm{Fe}$ depletion and $\mathrm{Ni}$ enrichment ahead of an active crack tip, which is most likely an indication of a migrated boundary. It might be argued that GB migration occurs also at higher temperatures (800 to $1200{ }^{\circ} \mathrm{C}$ ), and is always an accelerating factor for $\mathrm{O}$ and $\mathrm{Cr}$ diffusivity. However, its impact is greater at lower temperatures because of the higher mismatch between lattice and GB diffusivity. Moreover, during high-temperature oxidation the presence of internal oxide particles in the proximity of GBs and the same depth of the intergranular oxide ${ }^{[61,62]}$ will constrain GBs movements. Therefore, based on the present and previous studies, ${ }^{[30,33,43]}$ DIGM is the likely mechanism by which $\mathrm{O}$ and $\mathrm{Cr}$ GB diffusion is enhanced and can explain the discrepancy between the extrapolated $\mathrm{O}$ and $\mathrm{Cr}$ diffusion coefficients and the experimentally measured ones.

The results and discussion presented in the present work and comparison with the previously published data $^{[30,33,43]}$ are able to provide for the first time the fundamental link between plant operation conditions and the accelerating environments used conventionally to accelerate the PIO and stress corrosion cracking propagation mechanisms. In particular, the presence of a marked $\mathrm{Cr}$ - and $\mathrm{Fe}$-depleted migrated region along with intergranular $\mathrm{Cr}_{2} \mathrm{O}_{3}$ and the ultrafine-scale Al- and Ti-oxide enrichment at the oxide tip in all the three environments is a confirmation that the mechanism responsible for the enhanced oxidation is the same.

\section{CONCLUSIONS}

1. Solution-annealed Alloy 600 specimens exposed to simulated primary water at $320{ }^{\circ} \mathrm{C}$ and superheated steam at $400{ }^{\circ} \mathrm{C}$ were susceptible to preferential intergranular oxidation.

2. The morphology of the intergranular oxide penetrations observed in this study showed marked similarities to those reported for specimens exposed at higher temperature $\left(480{ }^{\circ} \mathrm{C}\right)$ in the low-pressure $\mathrm{H}_{2}$-steam environment. The occurrence of $\mathrm{GB}$ migration, intergranular $\mathrm{Cr}_{2} \mathrm{O}_{3}$, and $\mathrm{Ti}$ and $\mathrm{Al}$ oxide formation in all three environments and at different temperatures demonstrated that the mechanism by which Alloy 600 oxidizes is the same. Furthermore, these results provide compelling evidence that $\mathrm{H}_{2}$-steam environment can be used as an effective accelerated test for the PWR primary water environment.

3. Detailed microstructural analysis of FIB-produced GB TEM specimens confirmed that the oxide formed at the $\mathrm{GBs}$ was $\mathrm{Cr}_{2} \mathrm{O}_{3}$ with a $\mathrm{Ti}$ and $\mathrm{Al}$ core oxide at the innermost tip. Although Ti and $\mathrm{Al}$ are present in Alloy 600 in low levels, their presence may have a role in the PIO process.

4. Detailed TEM characterization of Alloy 600SA specimens confirmed that GB migration occurred during the exposure to super-heated steam at $400{ }^{\circ} \mathrm{C}$ and strongly suggested that the same mechanism is also active at $320^{\circ} \mathrm{C}$ in PWR primary water.

5. DIGM is believed to be the accelerating mechanism for enhanced $\mathrm{O}$ and $\mathrm{Cr}$ GB diffusivity especially at temperatures where there is a large mismatch between lattice and GB diffusivity; this can also explain the discrepancy between extrapolated diffusion coefficients from higher temperatures and the one required to account for the observed crack growth rates.

\section{ACKNOWLEDGMENTS}

The authors thank AREVA for financial support. Also, MGB and FS acknowledge the EPSRC programme (EP/JO21172/1) for support. Funding for the aberration-corrected FEI Titan G2 80-200 200S/TEM and the associated research capability of the Nuclear Advanced Manufacturing Research Centre at the School of Materials, University of Manchester, Manchester UK was provided by HM Government (UK). 


\section{OPEN ACCESS}

This article is distributed under the terms of the Creative Commons Attribution 4.0 International License (http://creativecommons.org/licenses/by/4.0/), which permits unrestricted use, distribution, and reproduction in any medium, provided you give appropriate credit to the original author(s) and the source, provide a link to the Creative Commons license, and indicate if changes were made.

\section{REFERENCES}

1. D. Van Rooyan: Corrosion, 1975, vol. 31, pp. 327-37.

2. E. Serra: EPRI Np-2114-SR, Palo Alto, CA, Electric Power Research Institute, 1981.

3. R.W. Staehle: Proc. Control of Corrosion on the Secondary Side of Steam Generators, Houston, TX: NACE, 1996, p. 135.

4. H. Coriou, R. Grall, M. Le Gall, and S. Vettier: 3(e) Colloque de metallurgie Corrosion, Centre d'Etudes Nucleaires de Saclay, North Holland Publishing Co., Amsterdam, Holland, 1959, p. 161.

5. P.L Andresen, R. Reid and J. Wilson: in Proceedings of the 14th International Symposium on Environmental Degradation of Materials in Nuclear Power System-Water Reactors, Mineral, Metals and Materials Society/AIME, 2009, pp. 345-372.

6. Y. Qiu, T. Shoji, and Z. Lu: Corrosion Science, 2011, vol. 53, pp. 1983-89.

7. G.P. Airey: NP-3051, Electric Power Research Institute, Palo Alto, California, 1983

8. R. Bandy and D. Van Rooyen: Corrosion, 1984, vol. 40, pp. 425-30.

9. P.M. Scott: in Proceedings of the 9th International Symposium on Environmental Degradation of Materials in Nuclear Power System-Water Reactors, Mineral, Metals and Materials Society/ AIME, 1999, pp. 3-14.

10. T.S. Bulischeck and D. Van Rooyen: Corrosion, 1981, vol. 37, pp. 597-607.

11. P. Kritzer: J. Supercrit. Fluids, 2004, vol. 29, pp. 1-29.

12. G. Economy, R.J. Jacko, and F.W. Pement: Corrosion, 1987, vol. 43 , pp. 727-34.

13. Tayler. Moss and Gary.S. Was: Metall. Mater. Trans., 2017, vol. 48A, pp. 1613-28.

14. J. Lindsay, F. Scenini, X. Zhou, G. Bertali, Robert A. Cottis, M.G. Burke, F. Carrette, and F. Vaillant: in Proceedings of the 16th International Symposium on Environmental Degradation of Materials in Nuclear Power System-Water Reactors, Minerals, Metals and Materials Society/AIME, 2013.

15. P. Combrade, P.M. Scott, M. Foucault, E. Andrieu, and P Marcus: in Proceedings of the $12^{\text {th }}$ International Symposium on Environmental Degradation of Materials in Nuclear Power System-Water Reactors, TMS, 2005, p. 883.

16. P.M. Scott, and M. Le Calvar: in Proceedings of the 6th International Symposium on Environmental Degradation of Materials in Nuclear Power Systems-Water Reactors, (TMS/AIME), 1993 pp. 657-670.

17. P.M. Scott, and P. Combrade: in Proceedings of the 11th International Symposium on Environmental Degradation of Materials in Nuclear Power System- Water Reactors, Minerals, Metals And Material Society/AIME, 2003, pp. 29-36.

18. D.A. Woodford and R.H. Bricknell: Treatise Mater. Sci. Technol., 1982, vol. 25, pp. 157-99.

19. R.G. Iacocca and D.A. Woodford: Metall. Mater. Trans. A, 1988, vol. 19 A, pp. $2305-13$

20. R.W. Staehle, and Z. Fang: in Proceedings of the 9th International Symposium on Environmental Degradation of Materials in Nuclear Power System-Water Reactors, Mineral, Metals and Materials Society/AIME, 2000, p. 107.

21. K. Fujii, K. Fukuya, and N. Nakajima: Mechanism of Material Degradation and Non-destructive Evaluation in Light Water Reactors, 2002, pp. 165-178.

22. R.C. Newman, T.S. Gendron, and P.M. Scott: in Proceedings of the 9 th International Symposium on Environmental Degradation of
Materials in Nuclear Power System-Water Reactors, Mineral, Metals and Materials Society/AIME, 2000, pp. 79-93.

23. L.E. Thomas and S.M. Bruemmer: Corrosion, 2000, vol. 55 (6), pp. 572-87.

24. S. Lozano-Perez and J.M. Titchmarsh: Mater. High Temp., 2003, vol. 20 (4), pp. 573-79.

25. G. Bertali, F. Scenini, M.G. Burke: Fontevraud 8 (2014)

26. S.Y. Persaud, A. Korinek, J. Huang, G.A. Botton, and R.C. Newman: Corros. Sci., 2014, vol. 86, pp. 108-122.

27. P. Scott: Mechanism of Material Degradation and Non-destructive Evaluation in Light Water Reactors, 2002, pp. 107-118.

28. S.Y. Persaud, A. Korinek, and R.C. Newman: Corros. Sci., 2015, vol. 90 , pp. 606-613.

29. A. Stratulat, D.E. Armstrong, and S.G. Roberts: Corros. Sci., 2016, vol. 104, pp. 9-16.

30. G. Bertali, F. Scenini, and M.G. Burke: Corros. Sci., 2015, vol. 100 , pp. 474-83.

31. D.K. Schreiber, M.J. Olszta, D.W. Saxey, K. Kruska, K.L. Moore, S. Lozano-Perez, and S.M. Bruemmer: Microsc. Microanal., 2013, vol. 19, pp. 676-87.

32. M.J. Olszta, D.K. Schreiber, M.B. Toloczko, S.M Bruemmer: in Proceedings of the 16th International Symposium on Environmental Degradation of Materials in Nuclear Power System-Water Reactors, Minerals, Metals and Materials Society/AIME, 2013.

33. G. Bertali, F. Scenini, J. Lindsay, B. Winiarski, X. li Zhong, M.G. Burke: in Proceedings of the 16th International Symposium on Environmental Degradation of Materials in Nuclear Power System-Water Reactors, Minerals, Metals and Materials Society/ AIME, 2013

34. F. Scenini, R.C. Newman, R.A. Cottis, R.J. Jacko: in Proceedings of the 12th International Symposium on Environmental Degradation of Materials in Nuclear Power System- Water Reactors, Minerals, Metals and Materials Society/AIME, 2005, pp. 891-902.

35. B. Langelier, S.Y. Persaud, A. Korinek, T. Casagrande, R.C. Newman, and G.A. Botton: Acta Materialia, 2017, vol. 131, pp. $280-95$.

36. F. Scenini, R.C. Newman, R.A. Cottis, and R.J. Jacko: Corrosion, 2008, vol. 64, pp. 824-35.

37. A. Molander: in Woodhead Publishing Series in Energy, Damien Féron ed., Woodhead Publishing, Nuclear Corrosion Science and Engineering, 2012, pp. 408-437.

38. D. Morton, S.A. Attanasio, and G. Young: in Proceedings of the 10th International Symposium on Environmental Degradation of Materials in Nuclear Power System-Water Reactors, Mineral, Metals and Materials Society/NACE, 2001.

39. S.A. Attanasio, D. Morton, M.A. Ando, N.F. Panayotou, and C.D. Thompson: in Proceedings of the 10th International Symposium on Environmental Degradation of Materials in Nuclear Power System-Water Reactors, Mineral, Metals and Materials Society/ NACE, 2001).

40. T. Moss and G.S. Was: J. Electrochem. Soc., 2015, vol. 162, pp. C35-C41.

41. P.L. Andresen, J. Hickling, K.S. Ahluwalia, and J. Wilson: Corrosion, 2008, vol. 64, pp. 707-720.

42. D.S. Morton, S.A. Attanasio, G.A. Young, P.L. Andresen, T.M. Angeliu: in NACE Corrosion, Paper No 01117, Nace International, 2001

43. G. Bertali, F. Scenini, and M.G. Burke: Corros. Sci., 2016, vol. 111, pp. 494-507.

44. V.Y. Gertsman and S.M. Bruemmer: Acta Materialia, 2001, vol. 49, pp. 1589-98.

45. B. Alexandreanu, B.H. Sencer, V. Thaveeprungsriporn, and G.S. Was: Acta Materialia, 2003, vol. 51, pp. 3831-48.

46. H.J. Schenk: Mater. Perform., 1976, vol. 15 (3), pp. 25-33.

47. R.W. Staehle and J.A. Gorman: Corrosion, 2004, vol. 60 (1), pp. $39-54$.

48. C. Wagner: Elektrochem, 1959, vol. 63, pp. 772-82.

49. S.Y. Persaud, J. Smith, A. Korinek, G.A. Botton, and R.C. Newman: Corros. Sci., 2016, vol. 106, pp. 236-48.

50. R.W. Balluffi and J.W. Cahn: Acta Metallurgica, 1981, vol. 29 (3), pp. 493-500.

51. A.H. King: Int. Mater. Rev., 1987, vol. 32 (4), pp. 173-89.

52. J.W. Cahn, J.D. Pan, and B.W. Balluffi: Scripta Metallurgica, 1978, vol. 13, pp. 503-508. 
53. M. Sennour, P. Laghaoutaris, C. Guerre, and R. Molins: J. Nucl. Mater., 2009, vol. 393, pp. 254-66.

54. B. Langelier, S.Y. Persaud, R.C. Newman, and G.A. Botton: Acta Materialia, 2016, vol. 109, pp. 55-68.

55. R.C. Newman and F. Scenini: Corrosion, 2008, vol. 64, pp. 72126

56. D.P. Whittle, Y. Shida, G.C. Wood, F.H. Stott, and D.B. Bastow: Philos. Mag., 1982, vol. 46, pp. 931-49.

57. H. Ghonem and D. Zheng: Mater. Sci. Eng. A, 1992, vol. 150, pp. 151-60.
58. K. Fujii, K. Fukuya, and N. Nakajima: Trans. Atomic Energy Soc. Jpn., 2002, vol. 1 (2), pp. 127-33.

59. M. Hillert and G.R. Purdy: Acta Metallurgica, 1978, vol. 26, pp. 333-38.

60. K. Smidoda, W. Gottschalk, and H. Gleiter: Acta Metallurgica, 1978, vol. 26, p. 1833.

61. F.H. Stott, Y. Shida, D.P. Whittle, G.C. Wood, and B.D. Bastow: Oxid. Metals, 1982, vol. 18, pp. 127-46.

62. Y. Shida, F.H. Stott, D.B. Bastow, D.P. Whittle, and G.C. Wood: Oxid. Metals, 1982, vol. 18, pp. 93-113. 